Research Article

\title{
Development and Application of Model Test System for Reconstruction and Expansion of Existing Shallow Single-Hole Tunnel into Twin-Arch Tunnel
}

\author{
Yanling Jia $\mathbb{D}^{1,2,3}$ Aohui Ouyang $\mathbb{D}^{1},{ }^{1}$ Siyu Wang $\mathbb{D}^{1},{ }^{1}$ Xing Liang $\mathbb{D},{ }^{1}$ Bin Wang $\mathbb{D}^{1},{ }^{1}$ \\ Chang Liu $\mathbb{B},{ }^{1}$ and Fei Ye $\mathbb{D}^{1}$ \\ ${ }^{1}$ School of Highway, Chang'an University, Xi'an, Shaanxi 710064, China \\ ${ }^{2}$ Guangxi Key Laboratory of Road Structure and Materials, Nanning, Guangxi 530007, China \\ ${ }^{3}$ Guangxi Transportation Science and Technology Group Co., Ltd., Nanning, Guangxi 530007, China
}

Correspondence should be addressed to Aohui Ouyang; 2018121089@chd.edu.cn and Xing Liang; 2018121128@chd.edu.cn

Received 2 December 2020; Revised 29 December 2020; Accepted 16 January 2021; Published 28 January 2021

Academic Editor: Ma Jianjun

Copyright (๑) 2021 Yanling Jia et al. This is an open access article distributed under the Creative Commons Attribution License, which permits unrestricted use, distribution, and reproduction in any medium, provided the original work is properly cited.

In this study, we developed a tunnel excavation model test system to investigate the deformation and mechanical response of the surrounding rocks and tunnel structure during the reconstruction and expansion of an existing shallow single-hole tunnel into a twin-arch tunnel. A model test was conducted to study the variation in the ground surface settlement characteristics, surrounding rock pressure, and internal stresses of the supporting structure and midwall during the construction process. The influence of the excavation distance on displacements and structural stress between the faces of the left and right tunnels was analysed using numerical software. A comparison between the model test results and the monitoring and measurement construction results revealed a fairly consistent ground surface settlement, indicating that the system is stable and reliable and can be widely applied to laboratory model test research on tunnel excavation. Results show that the excavation of the first tunnel had a significant effect on the stability of the surrounding rock within the distance of a single-tunnel span behind the tunnel face. When the excavation distance between the two tunnels exceeded twice the length of the single-tunnel span, its effect on the stresses and deformation of the reconstructed twin-arch tunnel was negligible.

\section{Introduction}

With recent rapid social and economic development, the adaptation of existing road capacities and standards to development requirements has become challenging. Traffic congestion has become the daily norm, leading to the expansion or reconstruction of an increasing number of roads [1-5]. In 1983, Jack discussed the problems faced in freeway reconstruction processes. Serving as a control project, the traffic capacity of a tunnel restricts the road capacity; therefore, the reconstruction and expansion of existing tunnels or construction of new tunnels has become particularly crucial. Examples of tunnel reconstruction and expansion projects include the Tennozan Tunnel and Shikishimanai Tunnel in Japan, Nazzano Tunnel in Italy,
Damao Mountain Tunnel of Quanzhou-Xiamen freeway, Yuzhou Tunnel of Chongqing Airport Road, and Chongqing Eling Tunnel $[6,7]$.

Many experts and scholars have researched tunnel reconstruction and expansion. For example, Boston's Central Artery/Tunnel Project (CA/T) began in Boston (a northeastern U.S. city) and involved the reconstruction of the Ted Williams Tunnel that crossed the city centre. In the CA/T project, the issue of advance supports in tunnel reconstruction was presented. Through analysis and research, it was concluded that advance supports should be provided for any vulnerable segments that might occur during the tunnel reconstruction process; furthermore, several corresponding construction techniques were proposed $[8,9]$. Hong-Peng et al. [10] studied the pressure distribution in surrounding 
rocks during the reconstruction of tunnels with different disease types using an indoor model test, the results of which were compared with the numerical simulation results for verification. Sun [11] summarized the deformation patterns of the surrounding rock and the original and new linings during tunnel reconstruction, demonstrating the role of the original lining during reconstruction. Based on the project, wherein, a four-lane tunnel was expanded into an eight-lane tunnel, Lun-Hai et al. [12] researched the optimal construction excavation scheme for reconstructing and expanding a large cross-sectional tunnel under the weak surrounding rock condition through a model test and numerical simulation analysis. Zhang-Zhong et al. [13] derived the complex stress function for the lateral expansion and excavation of the existing tunnel and studied the surrounding rock stress and displacement characteristics during lateral excavation using numerical methods. Using numerical analysis models, Liu et al. [14] studied the mechanical responses of surrounding rock during tunnel construction and in-situ expansion processes under different excavation schemes and proposed a reasonable excavation scheme for the relying project. The excavation of an existing tunnel disturbs the surrounding rock, which is disturbed again during the construction and excavation of the tunnel reconstruction and expansion project. Such repeated and superimposed disturbances and evolutions accelerate the weathering of surrounding rock, and reduce its strength, integrity, and selfstability; thus, reconstruction and expansion in a disturbed surrounding rock lead to many challenges. Xue [15] discussed the advantages and disadvantages of different widening and reconstruction methods for separated and narrowly spaced twin-arch tunnels and used a model to verify the rationality of the in-situ method of unilateral widening of the original tunnel. $\mathrm{Li}$ [16] used the finite numerical analysis software MIDAS to analyse the deformation characteristics of a loess tunnel site after expansion, thus verifying the feasibility of the tunnel expansion plan.

Recently, twin-arch tunnels have rapidly developed in China. Several scholars have conducted studies on the design and construction of twin-arch tunnels [17-19]. Lai et al. [20] established a three-dimensional finite element model to study the seismic responses of shallow large-section twinarch tunnels; he argued that more attention should be paid to ground deformation caused by the oscillation of shallow tunnels under seismic loads. Based on the twin-arch tunnel project of Jinliwen (Jinhua-Lishui-Wenzhou) expressway, Lin and $\mathrm{He}$ [21] proposed a safe, economic, and reasonable construction method through a similarity model test. LinPing et al. [22] conducted a similarity model test based on the Xiaojinkou twin-arch tunnel of Guanghui (GuangzhouHuizhou) expressway, studied the construction method of the twin-arch tunnel, stability of the surrounding rock, and structural internal stress characteristics, and proposed the middle pilot tunnel construction method. Based on the twinarch tunnel of Yunnan Yuanmo expressway, Liu et al. [23], simulated the tunnel construction process through a model test and numerical calculation, obtaining the distributions of the surrounding rock displacement, stress, and plastic zone during the construction process. Based on the Great Wall Ridge twin-arch tunnel project, Shu-Chen et al. [24] combined the model test and numerical simulation methods and studied the changing mechanics of the surrounding rock and midwall during the construction process of the extremely shallow twin-arch tunnel. Tian et al. [25] determined the material mixing ratios for the tunnel surrounding rock, preliminary lining, and midwall structures through rapid and direct shear tests, as well as unconfined compressive tests. They also compared the model test and numerical simulation results and observed that the loosening zone of the surrounding rock exhibited an asymmetric distribution after the excavation of the twin-arch tunnel with partial pressure. Gao and Xue [26] focused on the partial pressure and weak surrounding rock condition and, using a finite element model, studied the stresses and deformations of the surrounding rock and supporting systems of the twin-arch tunnel under different excavation conditions. Zhang et al. [27] conducted a model test based on the Xinzuofang tunnel on the Lanzhou-Chongqing railway and researched the surrounding rock pressure distribution and structural stress characteristics of the unequal span twin-arch railway tunnel. Liu et al. [28] combined the model test and numerical simulation methods to study the surrounding rock displacement, stress, and pressure-arch distributions of the Loess twin-arch tunnel during the construction process; furthermore, they strengthened the support for the areas with multiple stress redistributions. Their research results effectively guided the design and construction of the twinarch tunnel, which significantly promoted the development of the twin-arch tunnel engineering technology in China. Based on the first Loess twin-arch tunnel, Mao et al. [29] analysed the water disaster susceptible areas. Based on the Hoek-Brown criterion, Li et al. [30] constructed the numerical-analytical solution for the failure mode of the surrounding rock of shallow twin-arch tunnels using the plastic mechanics' method. Zhang et al. [31] analysed the stress and displacement of the surrounding rock, burial depth, and variation in the sidewall earth thickness via theoretical research and numerical simulation.

However, few engineering projects have been implemented worldwide; wherein, existing tunnels are considered as the middle guide tunnel for their expansion into twinarch tunnels. For the newly-constructed tunnel, the center of the existing tunnel is considerably higher than that of the middle guide tunnel and thus, the top of the midwall must be well-consolidated with the top of the existing tunnel lining, resulting in a large discrepancy between the stress characteristics of the midwall structure and the new twin-arch tunnel. The disturbance caused by the existing tunnel accelerates the weathering and erosion of the surrounding rocks. Therefore, it is vital to accurately assess the impact of such disturbances on the surrounding rocks and appropriately exploit it for the design and construction of in situ tunnel reconstruction and expansion. There are almost no engineering examples that can be used as a reference for designing related parameters and construction schemes; therefore, effective, related studies need to be conducted to guide the design and construction. Thus, to study the 
deformation process and construction/mechanical response of the surrounding rocks and tunnel structures during reconstruction and expansion of an existing shallow singlehole tunnel into a large-span twin-arch tunnel, we developed a tunnel excavation model test system that could be reused and assembled ring-by-ring and conducted a model test for the construction process of the tunnel reconstruction and expansion project; we further analysed the dynamically varying characteristics of the ground surface settlement, surrounding rock pressure, and structural internal stresses of the supporting structures and the midwall during the reconstruction and expansion process. The influence of excavation distance between the left and right tunnel faces was analysed using numerical software, and the model test results were further compared and mutually verified using the construction monitoring and measurement results. The research results were subsequently used as a guide for designing the parameters and formulating the construction scheme. The research methods and results of this study can serve as a reference for similar projects in the future.

\section{Development of Tunnel Excavation Model Test System}

Majority of the traditional model test methods and equipment are single destructive tests, which cannot be employed repeatedly. Moreover, almost every test needs to be started from scratch, thereby consuming significant manpower, material resources, and time. The traditional test models are inefficient and the use of the relevant test equipment results in considerable wastage of resources. Therefore, it is of utmost importance to develop a tunnel excavation model test system that is applicable to the excavation of different types of surrounding rocks, is adaptable to different construction excavation schemes, is recyclable and reusable, can save model fabrication time and cost, and has relatively high efficiency for research, as well as other related advantages. To ameliorate the shortcomings of the existing model test methods, we developed a reusable tunnel excavation model test system that can be assembled ring-by-ring, as depicted in Figure 1.

\subsection{Model Test Device}

2.1.1. Mould for Structure Pouring. Tunnel lining structure models are shell structures of relatively small thicknesses, which are based on the similarity ratio. Furthermore, the lining structure must be prepared using one-piece moulding; it must have a uniform and seamless thickness and should be free of damage. After repeated trials, a universal PVC plate material was selected as the substrate and was machined into moulds according to the structural parameters of the lining. bolts and steel plates were used to fix the PVC plate moulds. The space composed of the PVC plate moulds represented the lining structure space. A feed opening was reserved at one end of the fixed steel plate and used as a mould for the lining structure. The midwall structure was prepared using the same technique. During demoulding, the fixed bolts and steel plates were removed first and followed by the successive removal of the PVC boards, thus preventing damage to the structure model due to overall demoulding, as depicted in Figure 1(a).

2.1.2. Mould for Preexcavation Part. The PVC plate was selected for the fabrication of the tunnel preexcavation mould. An advertising board engraving machine was applied for precise mould segmentation according to the similarity ratio, and the block segmentation abided by the actual excavation divisions. Selection of the PVC plate thickness was controlled by each cycle of the excavation footage; thus, each segment excavation was completed in one shot and the interference on the test (due to excavation disturbance) was mitigated. After numbering the blocks following the excavation order, they were connected in series using fixed bolts and steel plates at both ends. To reduce damage to the measuring elements and wires in the secondary lining during excavation, grooves were reserved in relevant positions in the preexcavation model, as required. The wires of the measuring elements were connected to the data acquisition instrument. This model test system combined the mould for the preexcavation part and the above lining structure model. It was buried in advance, in a material similar to the surrounding rock. When simulating the construction excavation, the bolts were loosened, and the PVC boards were successively removed according to the actual excavation segmentation to simulate the excavation segment and footage. The mould for the preexcavation part is illustrated in Figure 1(b).

2.1.3. Model Test Box. The base of the model test box adopted the steel-reinforced concrete structure. The base-level was strictly controlled to satisfy tunnel model tests with different burial depths and ensure the data accuracy of the model tests. After welding the profiled steels with precisely controlled dimensions into a frame, organic glass was used to fabricate the baffles for each segment block for convenient experimental observation. The preburied and preexcavation mould part used removable organic glass; thus, it is convenient to change the local organic glass for different test targets. A dial indicator beam was made of profiled steel and its lifting was precisely controlled using a graduated bolt to adapt to models with different burial depths and measure the ground surface settlement. The preexcavation mould and tunnel structure with installed measuring elements were accurately located and measuring elements were buried in the surrounding rock as required. The similarity material for the surrounding rock was backfilled to the ground surface height and the dial indicator was installed. The fabricated model test box of the twin-arch tunnel is illustrated in Figure 1(c).

\subsection{Similarity Relationship and Similarity Material.} According to the second similarity theorem and existing research [8-12], the important factors to consider the geometric similarity ratio $C_{1}$ of the model include the model box dimensions and prototype tunnel span. After determining the 


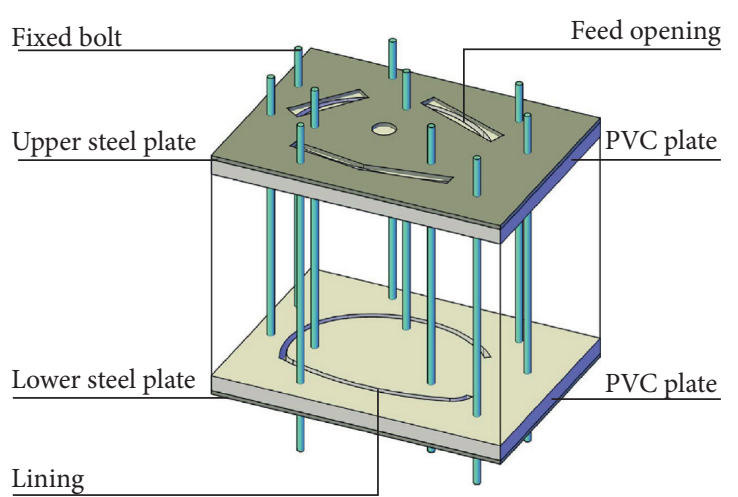

(a)

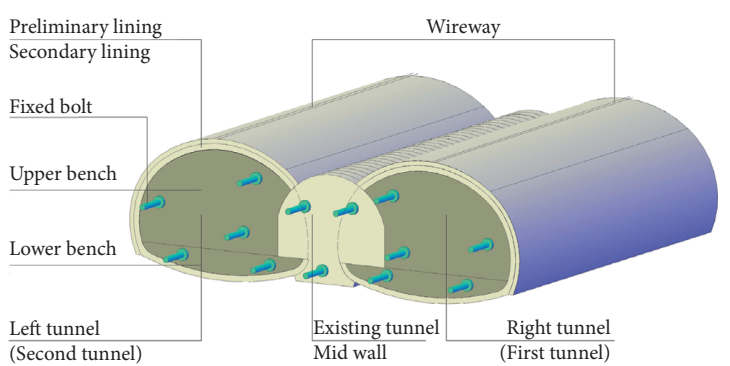

(b)

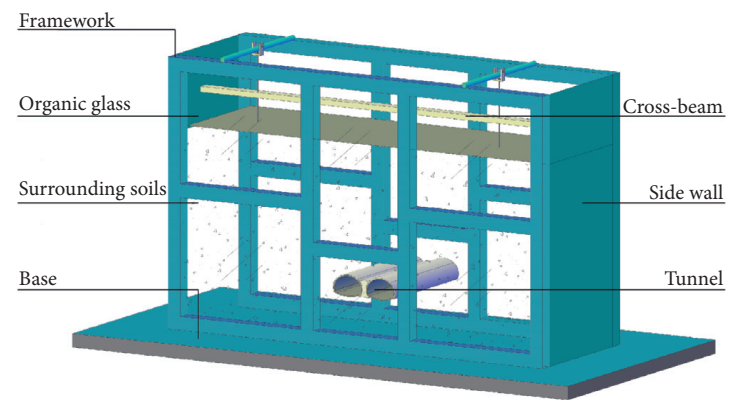

(c)

Figure 1: Tunnel excavation model test system. (a) Schematic of structure pouring mould. (b) Schematic of preexcavation model. (c) Schematic of model test box.

geometric similarity ratio, the similarity ratio relationships for the other parameters were also obtained. The model test box dimensions were $2854 \times 1722 \times 500 \mathrm{~mm}$, original tunnel span was $34.446 \mathrm{~m}$, and geometric similarity ratio $C_{1}$ of the model was determined to be 60 . The similarity ratios of the other parameters are listed in Table 1.

The accuracy with which the test results reflect the actual changes increases as the similarity between the materials and models and the actual project increases. The elastic modulus of the material can be calculated from the stress-strain curve of the test specimen, which can be obtained using an electronic universal testing machine; the friction angle and cohesion of the material can be measured using a quick direct shear test; and the uniaxial compressive strength (UCS) can be measured using a UCS test. After a series of tests and adjustments in a certain direction, similarity materials for surrounding rock and structures that conform to the test conditions were formulated.

2.2.1. Surrounding Rock. Quartz-cemented limestone was the primary rock in the following actual project, but the tunnel site was in a shallow area, where honeycomb holes were unevenly distributed in the rock mass; consequently, the surrounding rock was determined as Level II with poor mechanical properties.

The similarity material for the surrounding rock used in tunnel model tests is often formulated using raw materials, such as river sand, lime, gypsum, barite powder, fly ash, bentonite, shale soil, rosin, Vaseline, starch, alcohol, and water.
TABLE 1: Similarity parameters of the tunnel model test.

\begin{tabular}{lc}
\hline Parameter & Value \\
\hline Geometric similarity ratio $C_{l}$ & 60 \\
Bulk density similarity ratio $C_{\gamma}$ & 1 \\
Strain similarity ratio $C_{\varepsilon}$ & 1 \\
Poisson's similarity ratio $C_{\mu}$ & 1 \\
Friction angle similarity ratio $C_{\varphi}$ & 1 \\
Stress similarity ratio $C_{\sigma}$ & 60 \\
Elastic modulus similarity ratio $C_{E}$ & 60 \\
Cohesion similarity ratio $C_{c}$ & 60 \\
Area similarity ratio $C_{A}$ & $60^{2}$ \\
Moment of inertia similarity ratio $C_{I}$ & $60^{4}$ \\
\hline
\end{tabular}

The parameters of the similarity material for surrounding rock used in this test were as follows: a bulk density of $25-27 \mathrm{kN} / \mathrm{m}^{3}$, Poisson's ratio of $0.2-0.25$, an internal friction angle of $50-60^{\circ}$, a cohesion of $25-35 \mathrm{kPa}$, and an elastic modulus of $0.33-0.55 \mathrm{GPa}$. River sand, lime, gypsum, and barite powder were selected to prepare the surrounding rock similarity material. The bulk density, cohesion, Poisson's ratio, elastic modulus, internal friction angle, and UCS of the material under different mixing ratios were also analysed. Through parameter analysis, the final mixing ratio of river sand: gypsum: lime: barite powder: water was determined as $4: 0.6: 0.4: 1: 0.1$, yielding a surrounding rock similarity material that meets the test requirements. The parameter tests of the similarity material are depicted in Figure 2, and the parameters are listed in Table 2. 


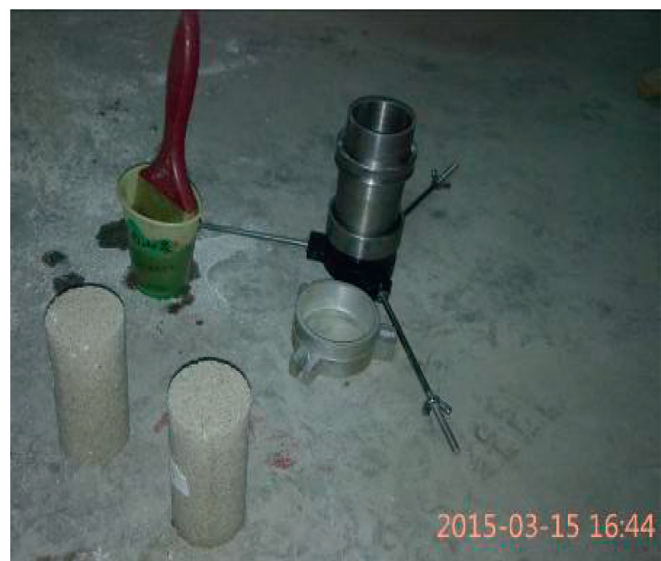

(a)

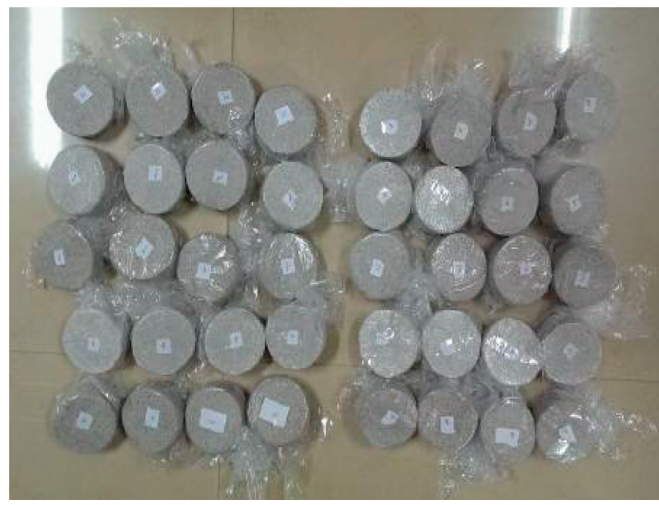

(c)

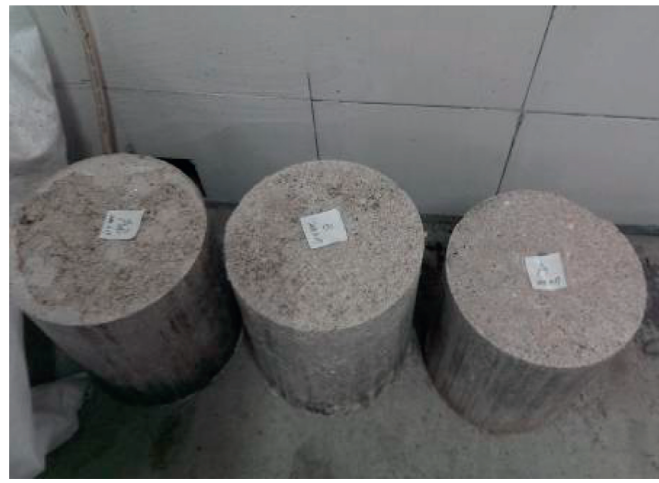

(e)

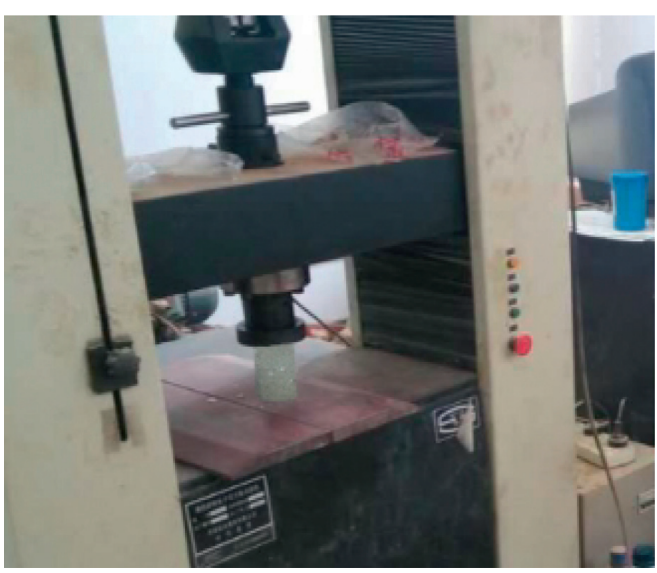

(b)

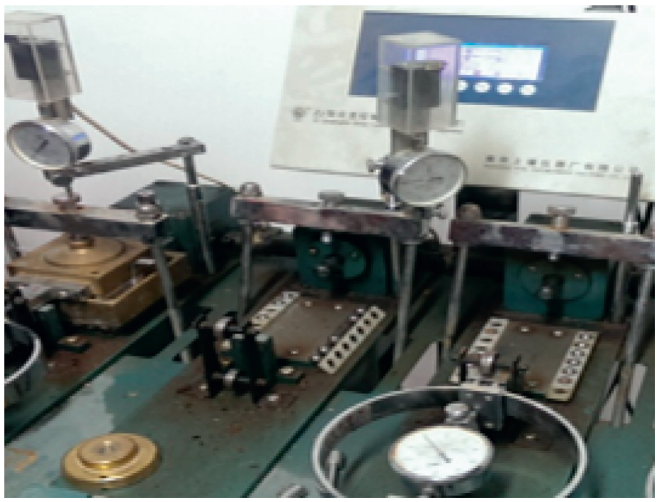

(d)

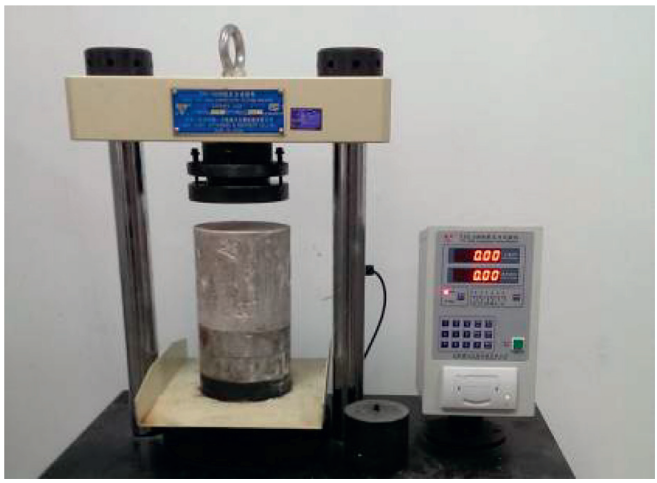

(f)

Figure 2: Parameter tests of similarity material for surrounding rock. (a) Elastic modulus test specimen. (b) Elastic modulus test. (c) Direct shear test specimens. (d) Direct shear test. (e) UCS test specimen. (f) UCS test.

TABLE 2: Mechanical indices of similarity materials prepared from sand, gypsum, lime, and barite powder.

\begin{tabular}{lccccccc}
\hline \multicolumn{1}{c}{ Number } & & Test group 1 & Test group 2 & Test group 3 & Test group 4 & Test group 5 & Average \\
\hline Bulk density & $\gamma\left(\mathrm{kN} / \mathrm{m}^{3}\right)$ & 21.8 & 22.7 & 22.2 & 23.1 & 21.6 & 22.28 \\
Elastic modulus & $\mathrm{E}(\mathrm{GPa})$ & 0.43 & 0.62 & 0.56 & 0.53 & 0.48 & 0.524 \\
Cohesion & $\mathrm{C}(\mathrm{kPa})$ & 20.4 & 31.3 & 29.5 & 34.9 & 19.7 \\
Poisson's ratio & $\mu$ & $0.19-0.22$ & $0.19-0.22$ & $0.19-0.22$ & $0.19-0.22$ & $0.19-0.22$ & $0.19-0.22$ \\
Internal friction angle & $\circ$ & 56.3 & 70.6 & 58.7 & 63.5 & 42.8 & 58.38 \\
UCS & $\sigma c(\mathrm{MPa})$ & 0.96 & 1.42 & 1.03 & 1.26 & 0.85 \\
\hline
\end{tabular}


2.2.2. Lining Structure and Midwall. Similarity materials for the tunnel lining structure and midwall are often formulated using gypsum powder, barite powder, glue, water, and other raw materials; some use metal or acrylic sheets as the materials and machine them into structural models. In the past, the majority of the similarity model tests have only focused on the stress and deformation of the secondary lining and have ignored the simulation of the preliminary lining of the tunnel. However, in an actual engineering project, the preliminary lining is an essential force-bearing structure and the stresses it is subjected to are often complicated.

Similar materials of different thicknesses-formulated using the same raw materials and mixing ratios as those of the midwall-were used in this test to simulate the preliminary and secondary linings of the tunnel. Gypsum, water, and industrial glue were mixed at a mass ratio of 1 : $0.8: 0.5$ to prepare the similarity materials for the midwall, as well as the preliminary and secondary linings. The target dimensions and the physical and mechanical properties are listed in Table 3.

\subsection{Tunnel Excavation Model Test System}

2.3.1. Data Acquisition Instrument. The test used the DH3816 static strain test system, which has high sensitivity and low drift and can perform multipoint cyclic sampling. Each module consists of six groups, including a total of 60 measuring points and six compensation measuring points. The data acquisition frequency was $0.1 \mathrm{~Hz}$.

2.3.2. Strain Gauge. The strain gauge was connected to the data acquisition instrument using a $1 / 4$ bridge circuit. Temperature compensation was performed for each measuring point to eliminate the interference of temperature changes on the test. To ensure the connection quality and reduce data drift, the wires were generally welded to the data acquisition instrument. The parameters of the strain gauge used in this test were as follows: resistance of $120 \Omega$, sensitive gate size of $3 \times 2 \mathrm{~mm}$, substrate size of $7.5 \times 2.8 \mathrm{~mm}$, lead wire length of $0.03 \mathrm{~m}$, and wiring length of $3 \mathrm{~m}$.

2.3.3. Pressure Box. A pressure box was used for testing the pressure changes or pressure values of the surrounding rock; it is often connected to the test system using a full-bridge circuit. The parameters of the pressure box used in this test were as follows: a diameter of $1 \mathrm{~cm}$ and a measurement range of $200 \mathrm{kPa}$.

2.3.4. Dial Indicator. The dial indicator was mainly used to monitor the changes in the ground surface settlement during tunnel excavation. The parameters of the dial indicator used in this test were as follows: a precision of $0.01 \mathrm{~mm}$ and a measurement range of $\pm 25 \mathrm{~mm}$.

\section{Application of the Tunnel Excavation Model Test System}

3.1. Engineering Background. A single-hole dual-lane secondary road tunnel (existing) in Guilin city-constructed and opened to traffic in 1993, $120 \mathrm{~m}$ in length, and $9 \mathrm{~m}$ in full width-is the core passage in and out of the city. Recently, there has been a rapid increase in traffic, particularly during the tourist seasons; thus, the tunnel has become a traffic bottleneck, with serious congestion and slow-moving traffic. Therefore, it is imperative to expand the existing tunnel, as illustrated in Figure 3. According to the actual terrain and geological conditions and considering the urban planning requirements, an in situ expansion scheme was determined after evaluating different alternatives. The existing tunnel, which was used as the middle guide tunnel, was reconstructed and expanded into a twin-arch tunnel, as depicted in Figure 4.

After reconstruction and expansion, the single-hole inner contour of the twin-arch tunnel was $14.803 \mathrm{~m}$ wide, maximum excavation width for the double-hole was $34.446 \mathrm{~m}$, and maximum burial depth was approximately $30 \mathrm{~m}$. Using conventional drilling and geophysical-geological survey methods, the surrounding rocks around the tunnel were preliminarily determined to be slightly weathered Devonian limestone, which exhibits relatively good integrity and is a Level II rock. The tunnel adopted a composite lining: the preliminary lining consisted of hanging mesh spray anchor shotcrete and a steel arch frame and the secondary lining was composed of moulded reinforced concrete. The parameters for the final support are listed in Table 4.

3.2. Fabrication of the Model. The surrounding rock material was prepared according to the mixing ratio of the similarity material; the moulds were used for pouring the lining structures; the preexcavation model was assembled simultaneously, as illustrated in Figure 5.

3.3. Measuring Point Layout. The layout of the measuring points in the model test is depicted in Figure 6. The change in the ground surface settlement during tunnel excavation was monitored using 14 dial indicator measuring points. To monitor the changes in the surrounding rock pressure, 13 and 7 micropressure boxes were set up at measuring points of 0 and $0.5 D$ from the excavation line, respectively, where $D$ denotes the single-hole span. On the outside of the midwall, six resistance strain gauge measuring points were arranged symmetrically in the clockwise direction. Furthermore, on the outside of the preliminary lining and the inside of the secondary lining, four and eight measuring points were set up, respectively, to monitor the strain and stress of the midwall and lining structures.

3.4. Model Test Excavation Process. The surrounding rock simulated in this test was a Level II rock, which is a hard material; thus, the full-face excavation method was adopted 
TABle 3: Thicknesses and mechanical parameters of linings and midwall prototypes and models.

\begin{tabular}{lccccc}
\hline Parameter & $\begin{array}{c}\text { Preliminary lining } \\
\text { thickness }(\mathrm{mm})\end{array}$ & $\begin{array}{c}\text { Secondary lining } \\
\text { thickness }(\mathrm{mm})\end{array}$ & $\begin{array}{c}\text { Midwall thickness } \\
(\mathrm{mm})\end{array}$ & $\begin{array}{c}\text { Elastic modulus } E \\
(\mathrm{GPa})\end{array}$ & $\begin{array}{c}\text { Compressive strength } R_{\mathrm{b}} \\
(\mathrm{MPa})\end{array}$ \\
\hline Prototype & $250+80.4$ & 450 & 2400 & $23-29.5$ & $12.5-16.7$ \\
Model & 5.5 & 7.5 & 40 & $0.38-0.49$ & $0.21-0.28$ \\
\hline
\end{tabular}

Note. The lining thickness of $80.4 \mathrm{~mm}$ is the shotcrete thickness that exhibits the same compressive rigidity (EA) as the profile steel support.

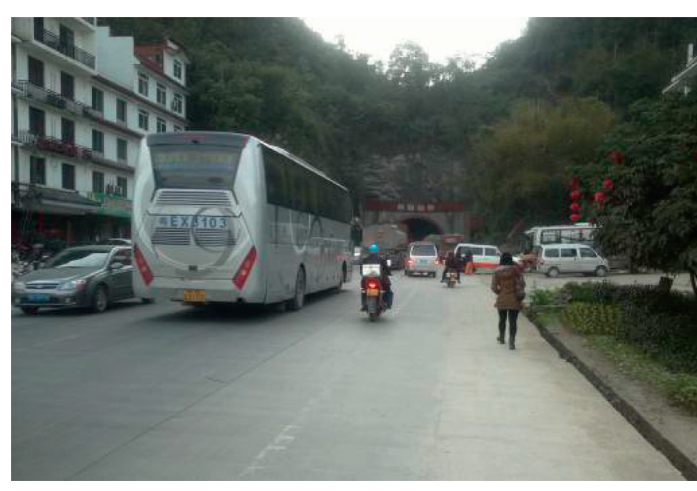

(a)

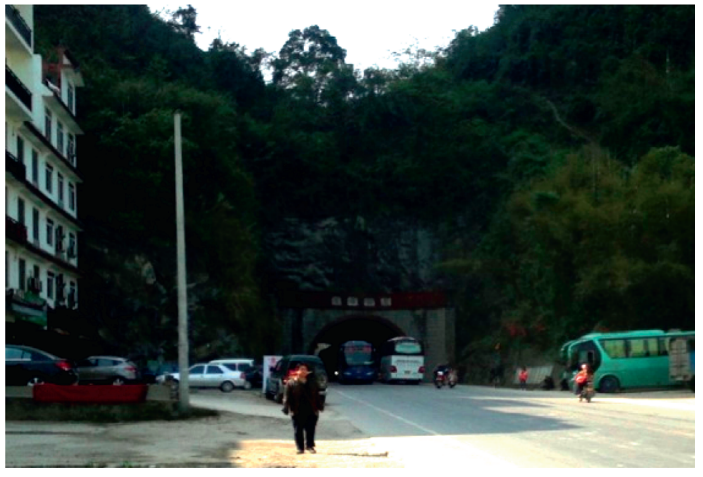

(b)

Figure 3: Congested road section of tunnel.
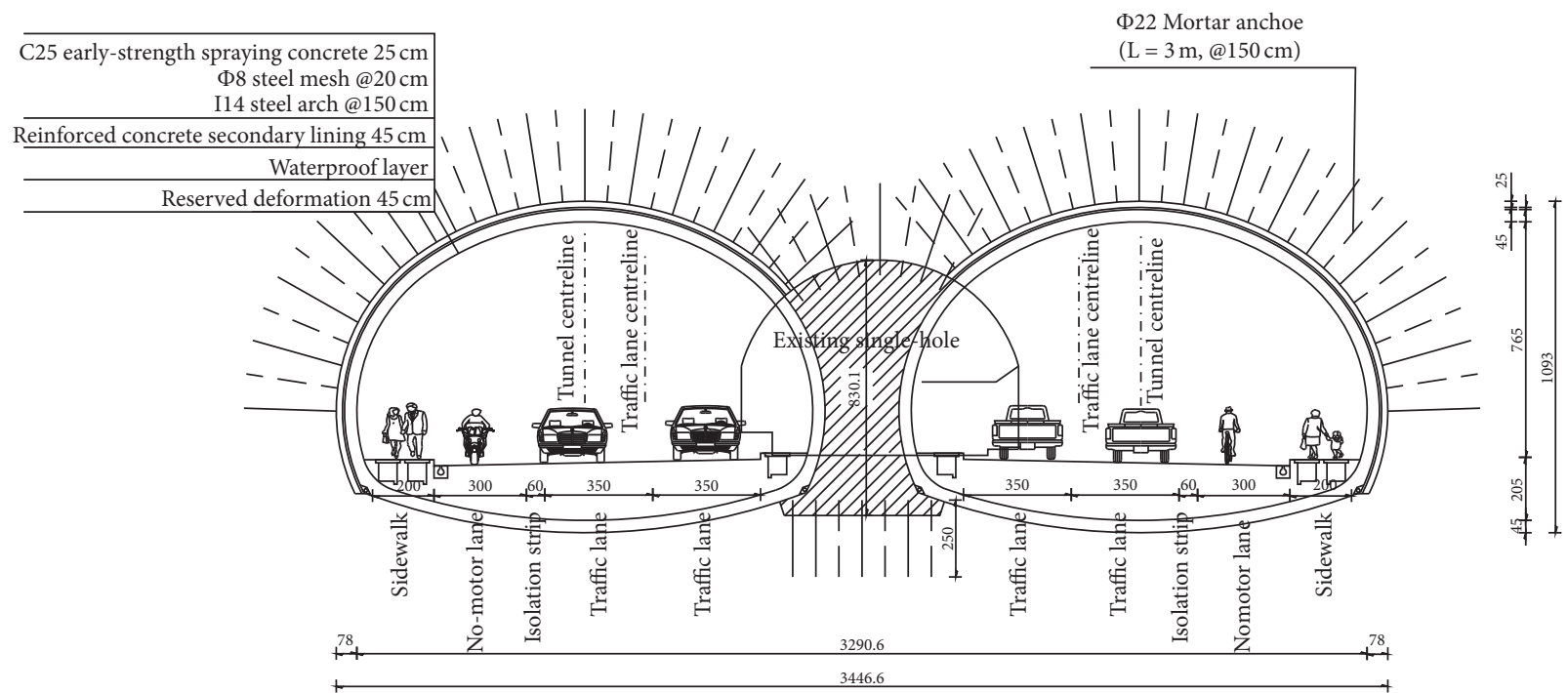

Figure 4: Cross section of reconstructed and expanded tunnel lining (unit: $\mathrm{cm}$ ).

TABLE 4: Tunnel support parameters $(\mathrm{cm})$.

\begin{tabular}{|c|c|c|c|c|c|c|c|c|c|}
\hline \multirow[t]{2}{*}{ Lining section } & \multicolumn{2}{|c|}{ Shotcrete } & \multicolumn{2}{|c|}{ Steel arch frame } & \multicolumn{3}{|c|}{$\begin{array}{l}\text { Mortar anchor bolt } \\
\quad(\Phi 22 \mathrm{~mm})\end{array}$} & \multirow[t]{2}{*}{ Reserved deformation } & \multirow[t]{2}{*}{ Lining thickness } \\
\hline & Location & Thickness & Model number & Spacing & Location & Length & Spacing & & \\
\hline Portal section & Arch, wall & 25 & $\mathrm{I} 16$ & 120 & Arch, wall & 300 & $120 \times 120$ & 8 & 45 \\
\hline Trunk section & Arch, wall & 25 & $\mathrm{I} 14$ & 150 & Arch, wall & 300 & $150 \times 150$ & 8 & 45 \\
\hline
\end{tabular}

to simulate the existing tunnel as well as the left and right tunnels on both sides. The detailed excavation sequence scheme is illustrated in Figure 7. The existing tunnel firstly was excavated; when the reading of dial indicator settled, we installed the midwall; after it finished, the right tunnel would be excavated, and the right tunnel was excavated then when the deformation and stress remained basically stable. 


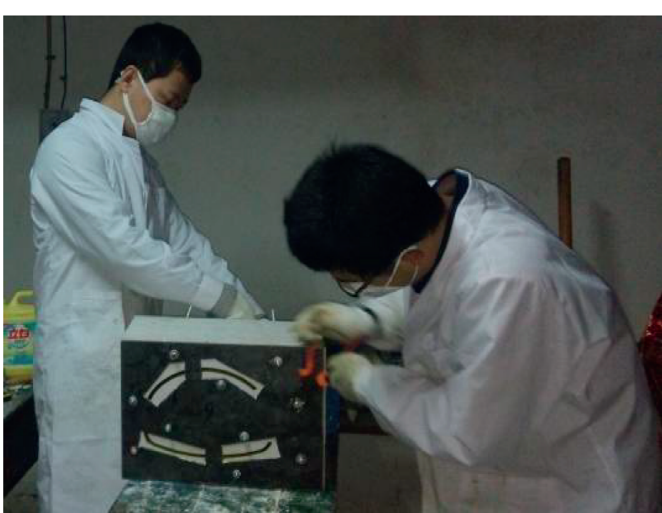

(a)

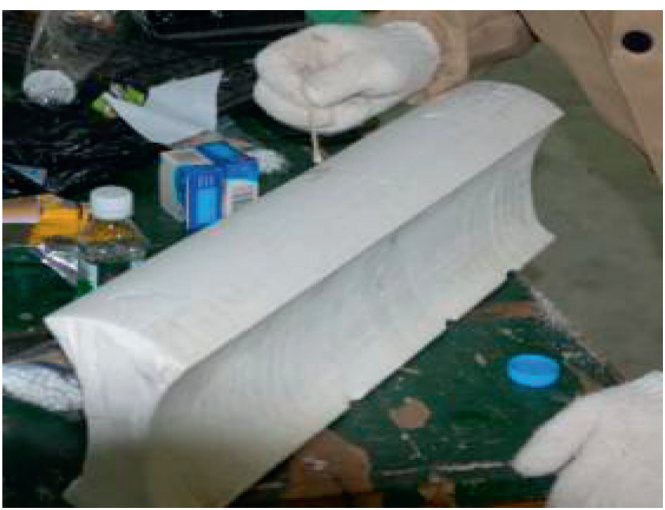

(c)

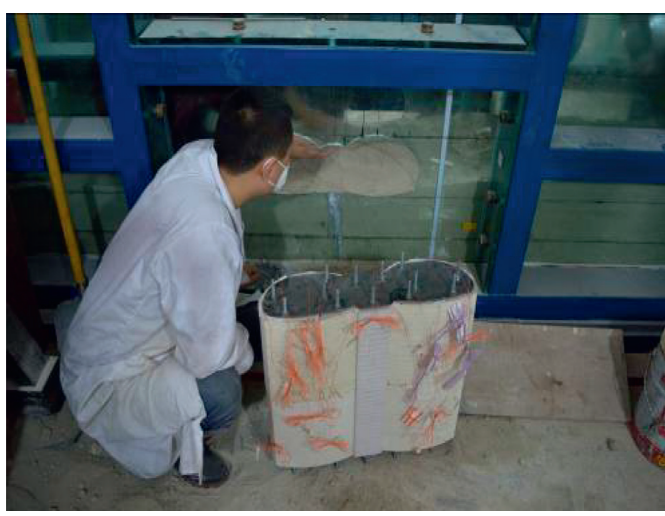

(e)

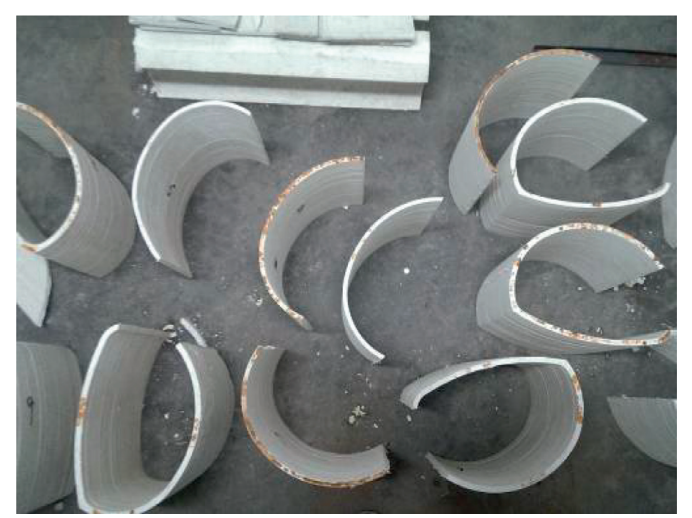

(b)

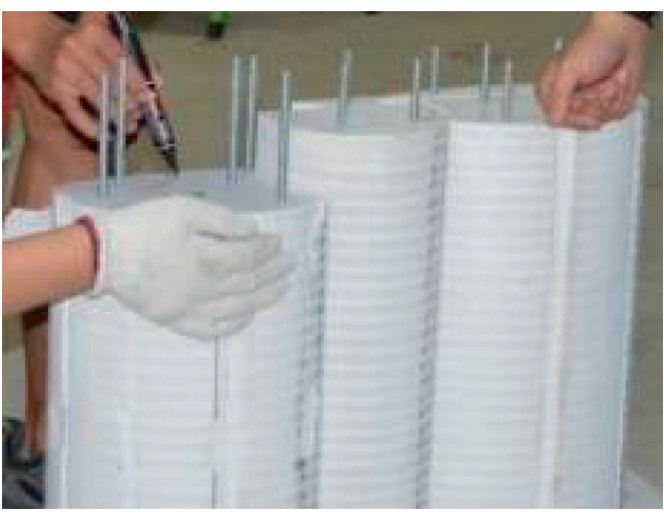

(d)

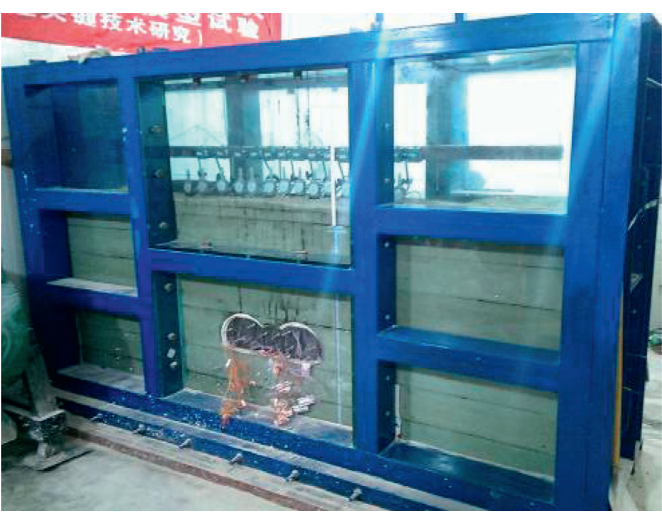

(f)

Figure 5: Model component fabrication. (a) Lining pouring mould. (b) Lining components. (c) Midwall. (d) Tunnel model. (e) Model and measuring element. (f) Buried tunnel model.

\subsection{Analysis of Model Test Results}

3.5.1. Ground Surface Settlement. For analysis, the test data were converted into settlement data corresponding to the tunnel prototype, according to the similarity ratios. The positive sign denotes uplift and the negative sign denotes settlement. The test results of the ground surface settlement are depicted in Figure 8. After completion of reconstruction and expansion, the ground settlement curve exhibited a " $W$ " shape. The top of the first tunnel (right tunnel) exhibited the largest ground surface deformation, the settlement of which reached $14.88 \mathrm{~mm}$. The ground surface deformation of the second tunnel (left tunnel) was $13.32 \mathrm{~mm}$. The top of the midwall exhibited the smallest ground surface deformation, and the settlement value was $5.52 \mathrm{~mm}$. The excavation of the second tunnel (left tunnel) demonstrated the most significant impact on the ground surface deformation, followed by the excavation of the existing tunnel, and the excavation of the first tunnel (right tunnel) caused the smallest ground surface deformation. This indicates that the midwall can effectively suppress the ground deformation induced by tunnel excavation. The surrounding rock had already severely deteriorated owing to the multiple disturbances caused by the constructions of the existing and first tunnels, 


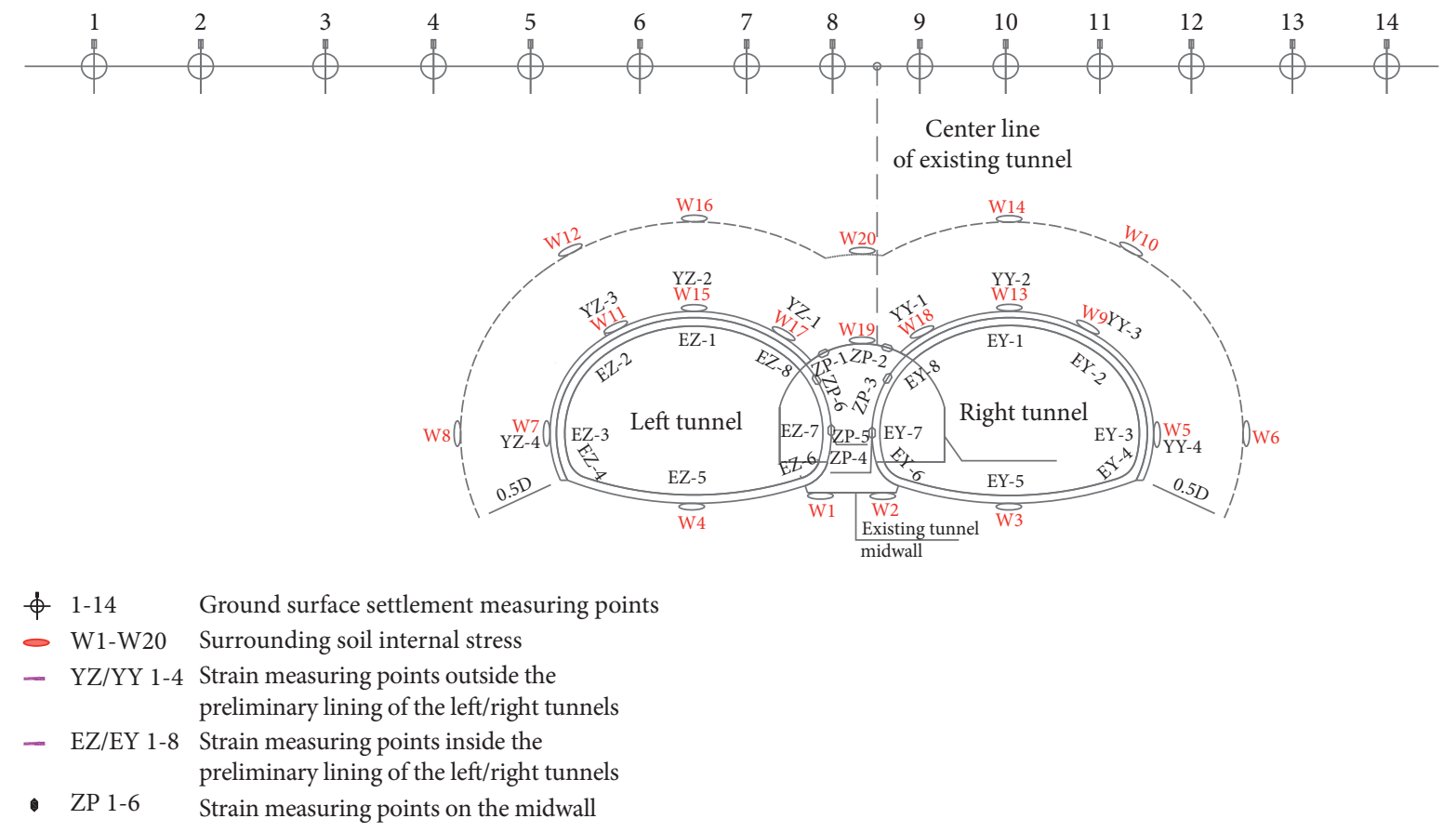

FIGURE 6: Measuring point arrangement.

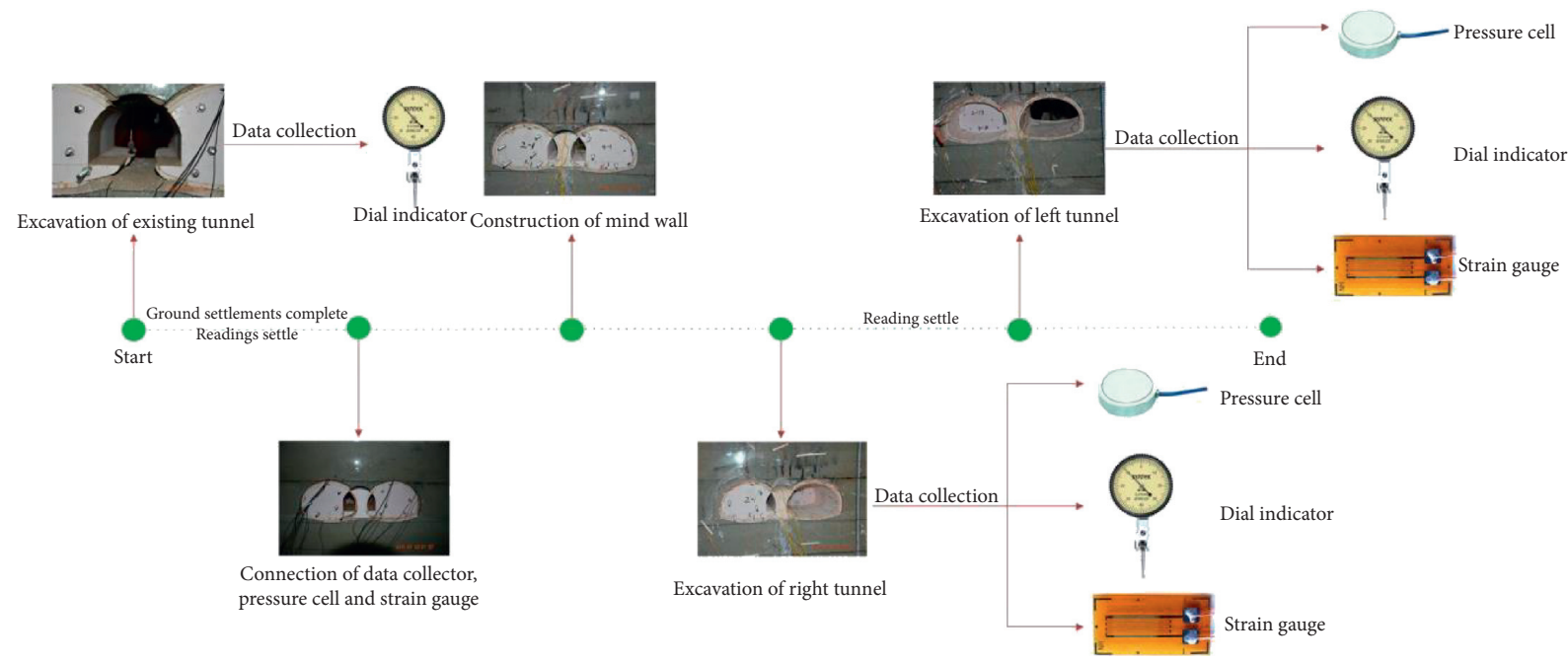

FIgURE 7: Model test excavation process.

which resulted in an increase in the ground surface deformation during the subsequent construction of the second tunnel. Furthermore, after the tunnel construction was completed, the maximum settlement was not on the ground surface immediately above the centreline of the left and right tunnels but slightly shifted toward the centre-ground surface of the existing tunnel. The excavation of the existing tunnel had already disturbed the surrounding rock and reduced its stability, leading to a relatively large settlement. For the reconstruction and expansion of shallow tunnels, regardless of the level of surrounding rock in the geological survey, the ground surface should be considered in the loosening range of the surrounding rock after being disturbed. The maximum ground settlement value on the first tunnel (right tunnel) side was greater than that of the left tunnel side, indicating that the surrounding rocks and structures on the right tunnel side were subjected to more disturbances and had worse stability.

3.5.2. Surrounding Rock Pressure. For analysis, the test data were converted into pressure data corresponding to the tunnel prototype, according to the similarity ratios. The positive sign denotes a decrease and the negative sign denotes an increase.

Figure 9 depicts that, during the tunnel excavation process, among the measuring points at $0.5 \mathrm{D}$ outside the excavation line, measuring point No. 10 on the right 


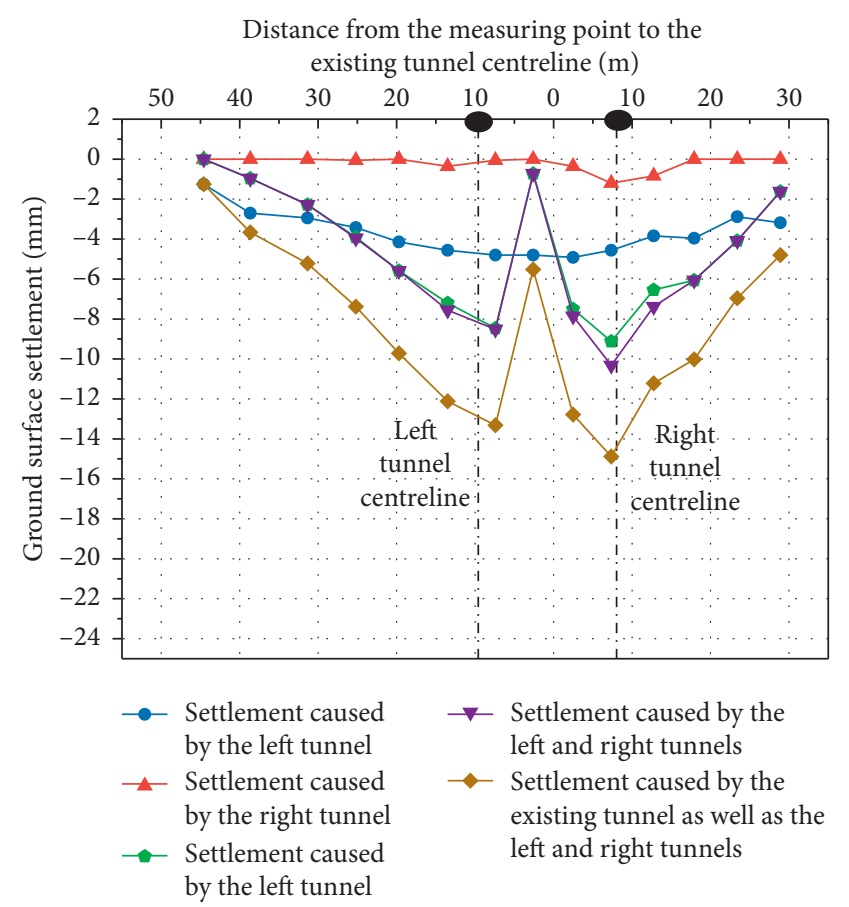

FIGURE 8: Ground surface settlement caused by construction.

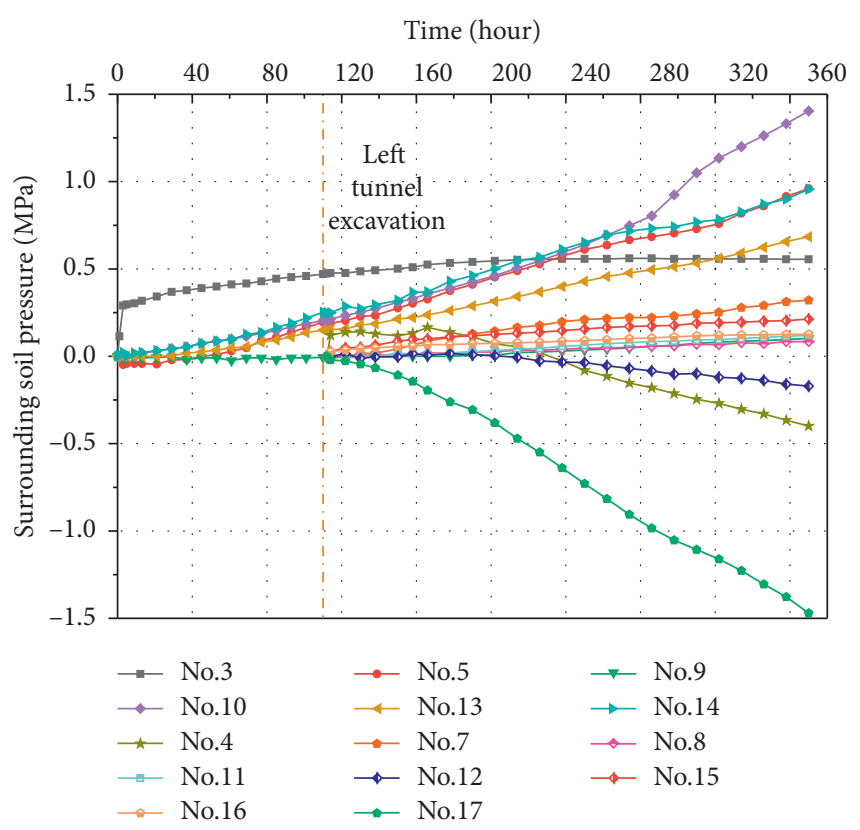

FIGURE 9: Stress history curve of surrounding rock.

shoulder of the right tunnel exhibited the largest reduction in the surrounding rock pressure $(1.4 \mathrm{MPa})$, followed by measuring point No. 14 on the crown of the right tunnel $(0.96 \mathrm{MPa})$; the other measuring points exhibited relatively small reductions in the surrounding rock pressure. This indicates that under the Level II rock condition, the surrounding rock loosening range caused by tunnel excavation construction could still exceed $0.5 D$.
During the tunnel excavation process, among the measurement points at $0 D$ outside the excavation line, measuring point No. 5 on the right-side wall of the right tunnel exhibited the largest reduction in surrounding rock pressure $(0.96 \mathrm{MPa})$; the surrounding rock pressure reduction at measuring point No. 13 on the crown was $0.68 \mathrm{MPa}$ and that at measuring point No. 18 on the left shoulder was $0.47 \mathrm{MPa}$. Measuring point No. 5 on the left-side wall of the left tunnel exhibited the largest reduction in the surrounding rock pressure $(0.32 \mathrm{MPa})$; the surrounding rock pressure reduction at measuring point No. 15 on the crown was $0.21 \mathrm{MPa}$ and that at measuring point No. 11 on the left shoulder was $0.12 \mathrm{MPa}$. The other measuring points exhibited relatively small reductions in the surrounding rock pressure.

In conclusion, the surrounding rock pressure reduction of the right tunnel was greater than that of the left tunnel, and the surrounding rock of the right tunnel was more disturbed than that of the left tunnel. Combined with the test results of the ground surface deformation, the loosening range of the surrounding rock-caused by the construction excavation of the tunnel reconstruction and expansion project simulated in this model test-could reach the ground surface (i.e., a burial depth of approximately $30 \mathrm{~m}$ ) and the surrounding rock loosening range was approximately $2 D$.

3.5.3. Structural Internal Stress. For analysis, the test data were converted into stress data corresponding to the tunnel prototype according to the similarity ratios. The positive sign denotes tension and the negative sign denotes compression.

(i) Midwall Stress. Figure 10(a) depicts the stress history curve of the midwall. The waist of the midwall (ZP-5 and ZP-4) was always under compression and the compressive stress first increased and subsequently decreased. The maximum compressive stress $(2.34 \mathrm{MPa})$ was at ZP-5 located on the left side, which was greater than the compressive stress $(1.67 \mathrm{MPa})$ at $\mathrm{ZP}-4$ on the right side. The shoulders of the midwall (ZP-6, $\mathrm{ZP}-3)$ were always under tension and the tensile stress demonstrated an increasing trend. The maximum tensile stress $(2.46 \mathrm{MPa})$ was at ZP-6 located on the left side, which was greater than the tensile stress $(1.21 \mathrm{MPa})$ at $\mathrm{ZP}-3$ on the right side. The left-top of the midwall (ZP-1) was always under tension and the maximum tensile stress measured at ZP-1 was $1.73 \mathrm{MPa}$; the top-right (ZP-2) was first tensioned and subsequently compressed and the maximum compressive stress measured at ZP-2 was $1.82 \mathrm{MPa}$.

The compressive stress subjected by the midwall was significantly lesser than the ultimate compressive strength of the C25 concrete at $19 \mathrm{MPa}$; the maximum tensile stress subjected by the midwall was $2.46 \mathrm{MPa}$, which was greater than the ultimate tensile strength of the C25 concrete at $2 \mathrm{MPa}$. Given that the structural steel reinforcement was not considered in the model fabrication process, the structural reinforcement ratio could be adjusted to $2 \%$ and above in actual engineering. According to the literature [14, 19], the elastic modulus of the reinforcement is converted into the equivalent elastic modulus of the concrete, i.e., 

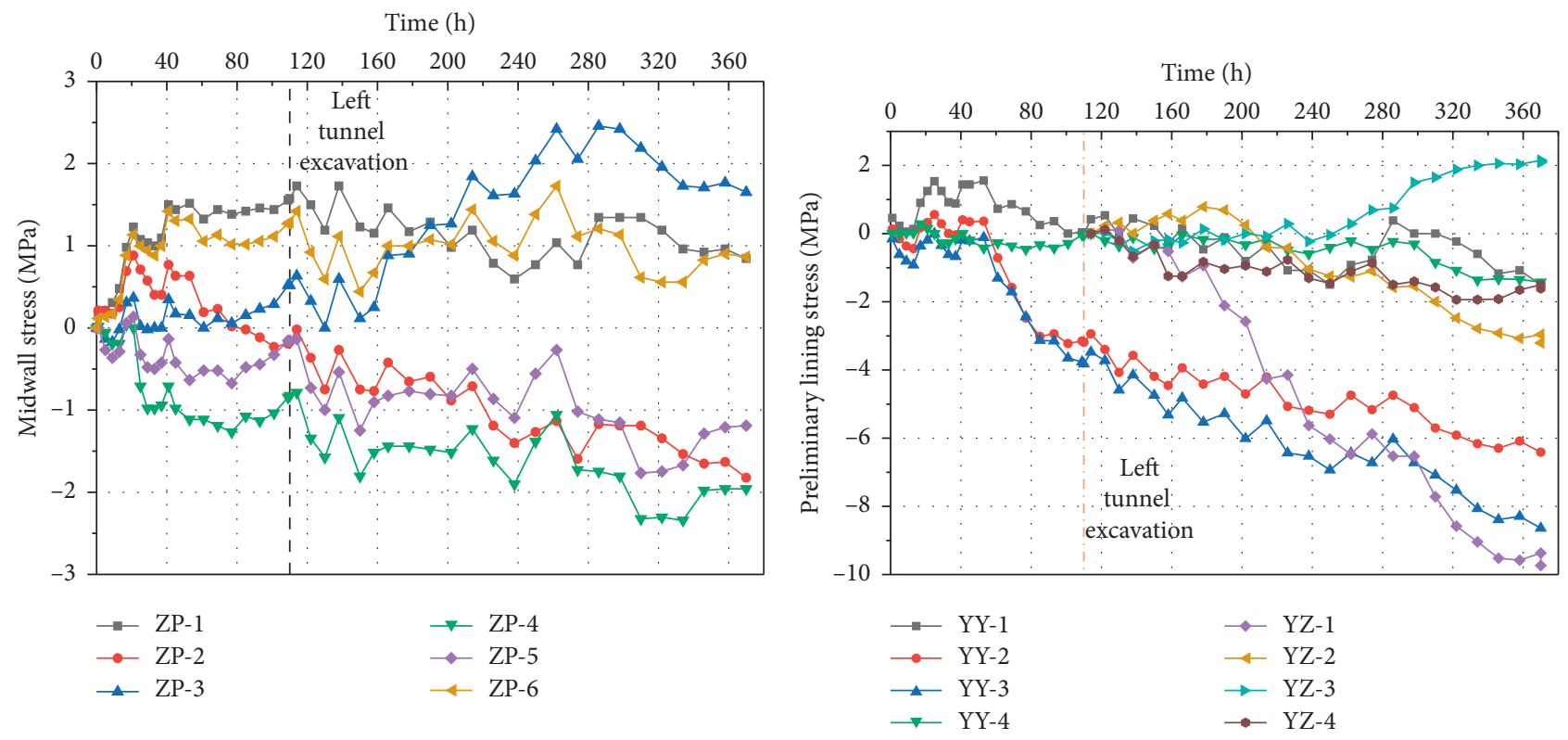

(a)

(b)

Time (h)

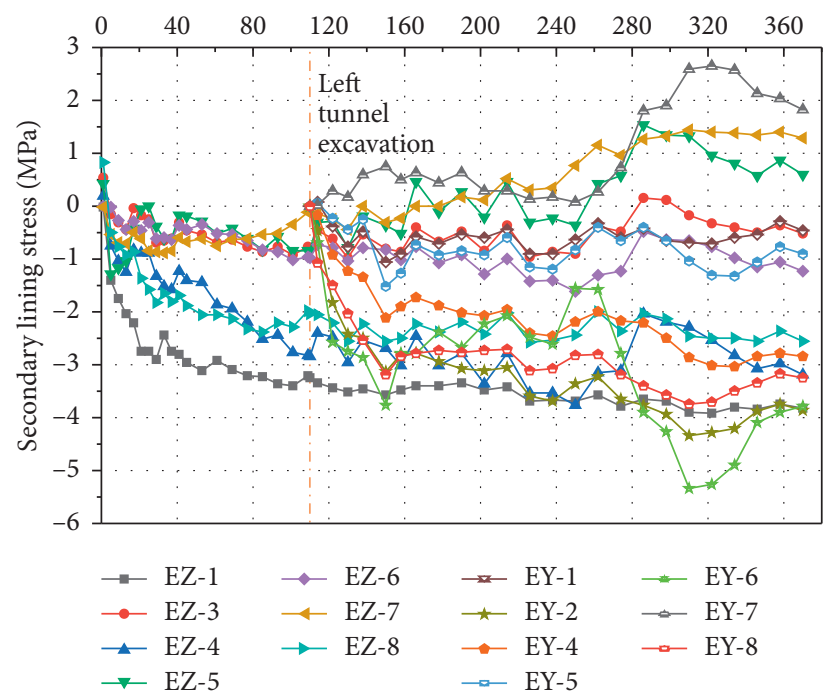

(c)

FIgURE 10: Time history curves of structural internal stresses. (a) Stress history curve of midwall. (b) Stress history curve of preliminary lining. (c) Stress history curve of secondary lining.

$$
E_{h}^{\prime}=\frac{E_{h}^{0}+A_{g} E_{g}}{A_{h}}
$$

where $E_{h}^{\prime}$ is the converted elastic modulus of the concrete; $E_{h}^{0}$ is the original elastic modulus of the concrete; $A_{h}$ is the cross-sectional area of the concrete; $E_{g}$ is the elastic modulus of the reinforcement; and $A_{g}$ is the cross-sectional area of the reinforcement.

When the reinforcement ratio was $2 \%$, the elastic modulus of the reinforced concrete structure was $33.7 \mathrm{MPa}$, which was greater than the elastic modulus of the C40 concrete $(33.5 \mathrm{MPa})$, exhibiting a high structural strength; the tensile stress subjected by the structure was lesser than the ultimate tensile strength of the $\mathrm{C} 40$ concrete of $2.7 \mathrm{MPa}$; thus, the structure was safe. According to the stress values obtained from the measuring points, it can be concluded that the excavation of the left and right tunnels imposed continuous disturbances on the midwall, particularly the excavation of the left tunnel, which had a greater impact on the midwall. The forces subjected by the midwall were relatively complicated. Attention should be paid to increase the strength of the midwall and mitigate the impact of construction on the midwall in the design.

(ii) Preliminary Lining Stress. Figure 10(b) depicts the stress history curve of the preliminary lining of the right tunnel. The 
left shoulder (YY-1) of the right tunnel was under tension and the tensile stress first increased and subsequently decreased; the maximum tensile stress was $1.56 \mathrm{MPa}$. The stress on the crown (YY-2) varied repeatedly between tension and compression, which was a complicated stress condition; the maximum tensile stress was $0.56 \mathrm{MPa}$, and the maximum compressive stress was $6.41 \mathrm{MPa}$. The right shoulder (YY-3) was under compression, and the maximum compressive stress was $8.64 \mathrm{MPa}$. The arch waist (YY-4) was mainly subjected to compression, and the maximum compressive stress was $1.42 \mathrm{MPa}$. The right shoulder (YZ-1) of the left tunnel was under compression, and the maximum compressive stress was $9.73 \mathrm{MPa}$. The crown (YZ-2) was first tensioned and subsequently compressed, which was also a complicated stress condition; the maximum tensile stress was $0.79 \mathrm{MPa}$, and maximum compressive stress was $3.21 \mathrm{MPa}$. The left shoulder (YZ-3) was mainly under tension, and the maximum tensile stress was $2.15 \mathrm{MPa}$; the left arch waist (YZ4) was under compression, and the maximum compressive stress was $1.94 \mathrm{MPa}$. The tensile stress subjected by the preliminary lining was greater than the ultimate tensile strength of the C25 concrete of $2.0 \mathrm{MPa}$, leading to the possibility of cracks in the shotcrete. As there was a steel arch frame in the preliminary lining, the cracks in the shotcrete did not affect the structural safety. The preliminary lining structures of the left/right tunnels close to the midwall were under a complicated stress condition and the stress values were large; thus, the support parameters of these sections should be strengthened in the design. Moreover, during construction, attention should be paid to reducing disturbances and ensuring structural stability.

\section{Numerical Analysis of Influence of Excavation Space}

Using the FLAC ${ }^{3 \mathrm{D}}$ numerical simulation software, the reconstruction and expansion of an existing tunnel into a multiarch tunnel was analysed, focusing predominantly on the stress/strain transmission mechanism between the left and right tunnels during construction.

4.1. Three-Dimensional Model and Parameters. As depicted in Figure 11, the geometric size of the three-dimensional model is $188 \times 90 \times 100 \mathrm{~m}$ and the buried depth $H$ is $30 \mathrm{~m}$, which is twice the single-span $D$ of the multiarch tunnel; the widths of the left and right sides of the model are five times that of the single-span $D$ of the multiarch tunnel.

There are 1.5 million meshes in the three-dimensional model. Horizontal displacement constraints are applied to the left and right boundaries, vertical displacement constraints are applied to the lower boundary, and the upper boundary is considered as a free surface. The parameters of surrounding rocks and supports adopted are shown in Table 5.

4.2. Analysis of Simulation Results. The "Design Specifications for Highway Tunnels" stipulate that the minimum excavation distance between the left and right tunnels of a

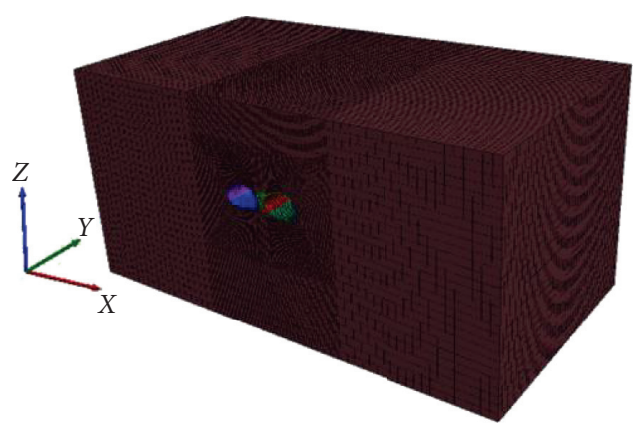

FIgURE 11: Three-dimensional model grid.

twin-arch tunnel should be greater than twice the tunnel span $(D)$. In the present study, excavation distances of $2 D$ and $4 D$ were successively used in the three-dimensional numerical simulation.

To analyse the effect of the excavation distance between the first and second tunnels on the mechanical behaviour of the supporting structure of the twin-arch tunnel, the right tunnel was bored, first at a distance of $2 D$ and then at a distance of $4 D$, followed by the left tunnel. Figure 12 shows the excavation process of the tunnels, and Figure 13 shows the arrangement of measuring points in the three-dimensional model.

To determine the effect of a single-tunnel excavation, we selected the excavation distance of $4 D$ for surface monitoring and analysis. Based on the cross-sectional monitoring of both tunnels, we were able to obtain the following surface settlement diagram, as shown in Figure 14:

Within $1 D$ of the excavation face of the right tunnel, the surface settlement caused by the excavation was relatively large. From $1 D$ to $2 D$, the surface settlement increased slightly and the midpoint of the settlement curve shifted toward the left tunnel (later-excavated tunnel). The maximum surface settlement occurred within the distance of $-1 D$ from the face of the left tunnel. Therefore, once the distance between the tunnel face and monitoring section exceeded $1 D$, the tunnel excavation had a minimal impact on the surface settlement of the monitoring section.

The stress and deformation of the midwall and supporting structures at the excavation distances of $2 D$ and $4 D$ were compared and analysed, respectively, as presented in Tables 6-8. It is evident from the results that when the excavation distance exceeds $2 D$, the stress and deformation of the twin-arch tunnel decreases as the distance increases; however, the change is negligible. Therefore, when the excavation distance exceeds $2 D$, it has a minimal impact on the stability of the twin-arch tunnel.

\section{Design and Construction Optimisation}

5.1. Construction Monitoring and Measurement Verification. The measuring point layout for ground surface settlement monitoring and measurement was the same as that in the model test. Measuring point No. 7 was positioned at the ground surface centre of the existing tunnel; measuring points No. 4 and No. 5 were positioned at the ground surface centre of the left tunnel; measuring points No. 9 and No. 10 
TABLE 5: Parameters of surrounding rocks and supports.

\begin{tabular}{|c|c|c|c|c|c|c|}
\hline Material & $\begin{array}{l}\text { Bulk density } \\
\left(\mathrm{kN} / \mathrm{m}^{3}\right)\end{array}$ & $\begin{array}{c}\text { Elastic modulus } \\
(\mathrm{GPa})\end{array}$ & $\begin{array}{l}\text { Poisson's } \\
\text { ratio }\end{array}$ & $\begin{array}{c}\text { Internal friction } \\
\text { angle }\left({ }^{\circ}\right)\end{array}$ & $\begin{array}{c}\text { Cohesion } \\
(\mathrm{MPa})\end{array}$ & $\begin{array}{l}\text { Thickness } \\
\text { (m) }\end{array}$ \\
\hline Surrounding rock & 27 & 20 & 0.25 & 50 & 1.5 & - \\
\hline $\begin{array}{l}\text { Preliminary lining of original } \\
\text { support }\end{array}$ & 23 & 23 & 0.2 & - & - & 0.45 \\
\hline Midwall & 23 & 31 & 0.2 & - & - & 2.4 \\
\hline Preliminary support & 23 & 23 & 0.2 & - & - & 0.25 \\
\hline Secondary lining & 23 & 29.5 & 0.2 & - & - & 0.45 \\
\hline
\end{tabular}

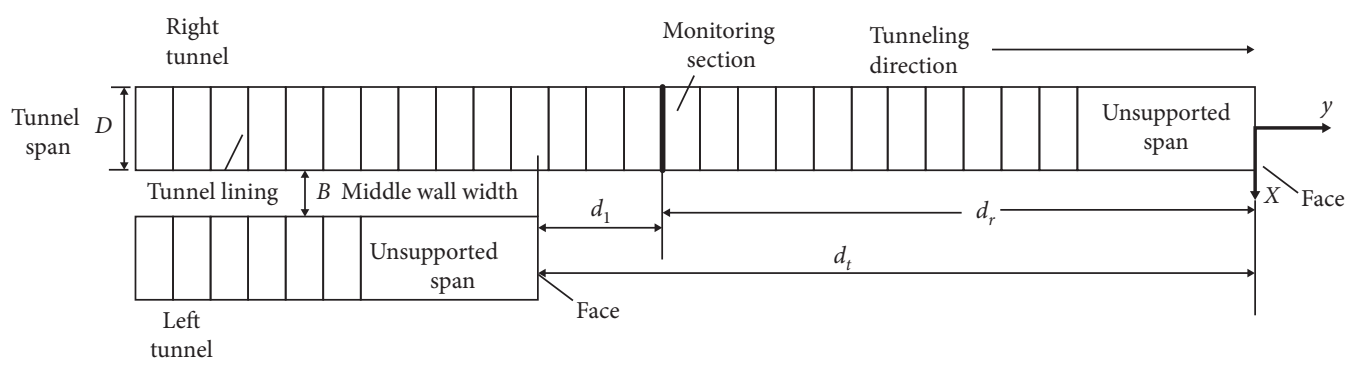

Figure 12: Diagram of tunnel excavation.

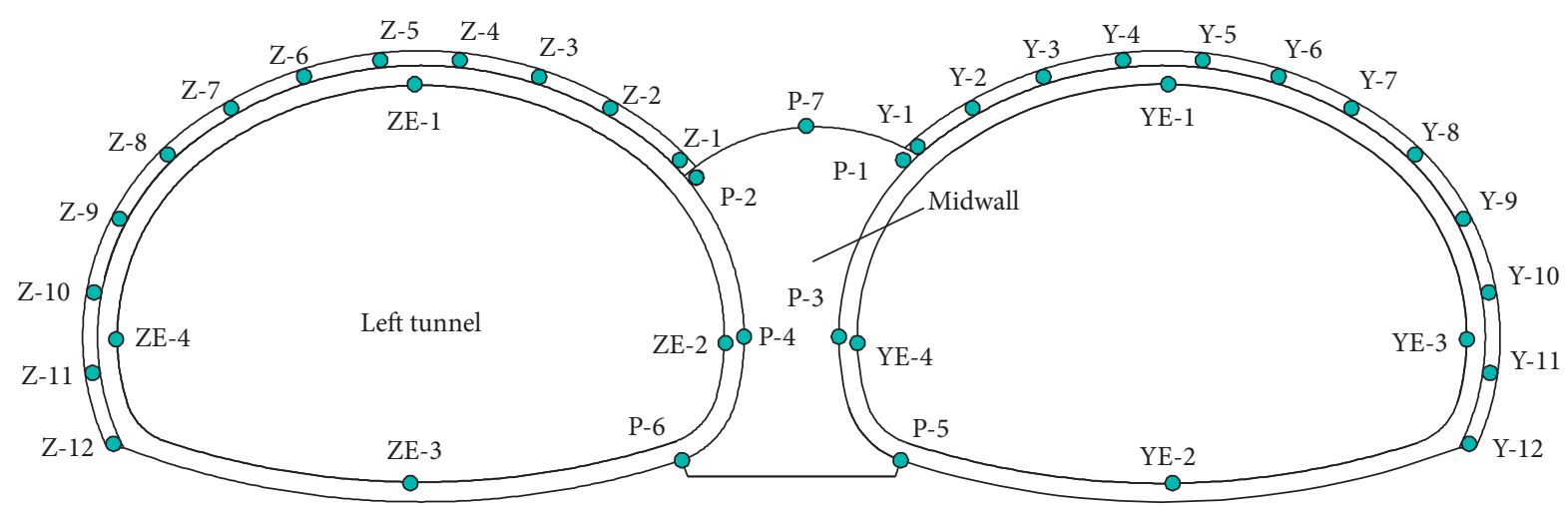

Figure 13: Arrangement of measuring points in the three-dimensional model.

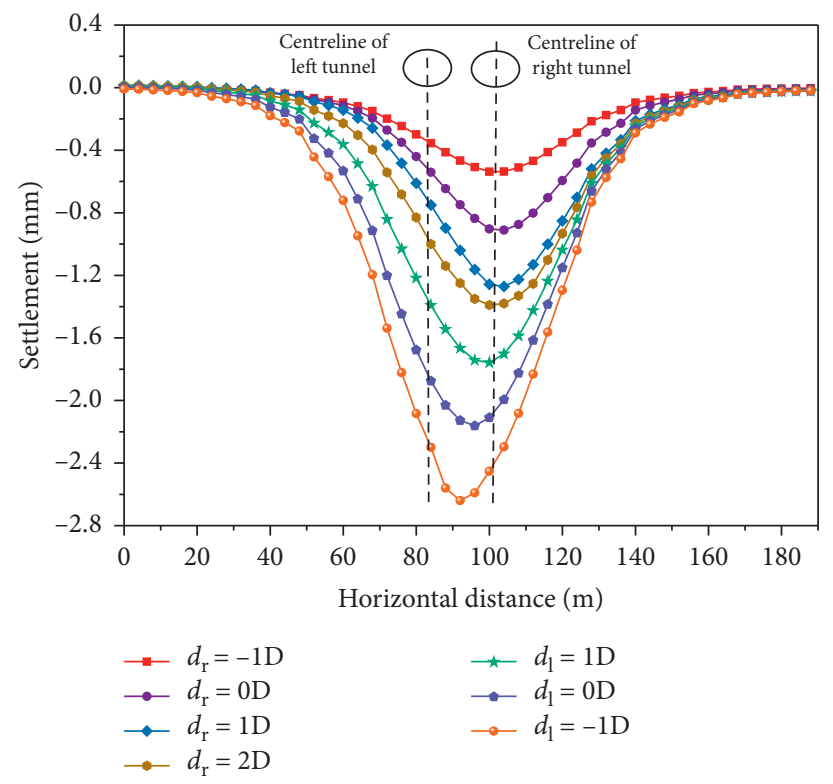

FIgURE 14: Surface settlement during tunneling. 
TABLE 6: Displacement of measuring points of secondary lining $(\mathrm{mm})$.

\begin{tabular}{lcccccc}
\hline \multirow{2}{*}{ Point } & \multicolumn{2}{c}{$4 D$} & \multicolumn{2}{c}{$2 D$} & \multirow{2}{*}{$\mathrm{A} / \mathrm{B}(\%)$} & $\mathrm{C} / \mathrm{D}(\%)$ \\
& $E_{\mathrm{Y}}(\mathrm{A})$ & $E_{\mathrm{Z}}(\mathrm{C})$ & $E_{\mathrm{Y}}(\mathrm{B})$ & $E_{\mathrm{Z}}(\mathrm{D})$ & & \\
\hline Y/ZE-1 & -3.58 & -3.63 & -3.59 & -3.63 & 99.68 & 99.97 \\
Y/ZE-2 & 2.98 & 3.03 & 3.00 & 3.03 & 99.58 & 99.82 \\
Y/ZE-3 & 0.55 & 0.75 & 0.55 & 0.70 & 98.90 & 107.47 \\
Y/ZE-4 & -0.03 & -0.62 & -0.04 & -0.61 & 96.03 & 101.10 \\
\hline
\end{tabular}

Note. $E_{\mathrm{Y}}$ is the displacement of a secondary-lining monitoring point of the right tunnel after the excavation of both tunnels is completed. $E_{\mathrm{Z}}$ is the displacement of a secondary-lining monitoring point of the left tunnel after the excavation of both tunnels is completed.

TABle 7: Axial force on both tunnels $(\mathrm{kN})$.

\begin{tabular}{lllllll}
\hline \multirow{2}{*}{ Point } & \multicolumn{2}{c}{$4 D$} & \multicolumn{2}{c}{$2 D$} & \multirow{2}{*}{$\mathrm{A} / \mathrm{B}(\%)$} & $\mathrm{C} / \mathrm{D}(\%)$ \\
& $F_{\mathrm{Y}}(\mathrm{A})$ & $F_{\mathrm{Z}}(\mathrm{C})$ & $F_{\mathrm{Y}}(\mathrm{B})$ & $F_{\mathrm{Z}}(\mathrm{D})$ & & \\
\hline $\mathrm{Y} / \mathrm{Z}-1$ & -102.34 & -195.94 & -104.05 & -197.64 & 98.36 & 99.14 \\
$\mathrm{Y} / \mathrm{Z}-2$ & -83.80 & -97.41 & -82.88 & -99.53 & 101.11 & 97.87 \\
$\mathrm{Y} / \mathrm{Z}-3$ & -42.17 & -43.39 & -40.71 & -43.87 & 103.57 & 98.90 \\
$\mathrm{Y} / \mathrm{Z}-4$ & -20.96 & -19.06 & -20.27 & -19.06 & 103.40 & 99.99 \\
$\mathrm{Y} / \mathrm{Z}-5$ & -20.38 & -13.51 & -19.41 & -13.82 & 104.99 & 97.78 \\
$\mathrm{Y} / \mathrm{Z}-6$ & -34.93 & -25.48 & -34.35 & -25.73 & 101.68 & 99.05 \\
$\mathrm{Y} / \mathrm{Z}-7$ & -63.47 & -53.51 & -64.09 & -54.14 & 99.03 & 98.82 \\
$\mathrm{Y} / \mathrm{Z}-8$ & -107.16 & -98.89 & -107.90 & -99.93 & 99.31 & 98.96 \\
$\mathrm{Y} / \mathrm{Z}-9$ & -167.22 & -158.48 & -168.37 & -159.69 & 99.32 & 99.25 \\
$\mathrm{Y} / \mathrm{Z}-10$ & -233.47 & -222.16 & -234.76 & -223.14 & 99.45 & 99.56 \\
$\mathrm{Y} / \mathrm{Z}-11$ & -277.93 & -266.92 & -280.36 & -267.60 & 99.14 & 99.75 \\
$\mathrm{Y} / \mathrm{Z}-12$ & -222.85 & -219.72 & -225.28 & -220.31 & 98.92 & 99.73 \\
\hline
\end{tabular}

Note. $F_{Y}$ is the axial force of a monitoring point on the primary lining of the right tunnel after the excavation of both tunnels is completed; $F_{Z}$ is the axial force of a monitoring point on the primary lining of the left tunnel after the excavation of both tunnels is completed.

TABLE 8: Minimum principal stress of midwall monitoring points (MPa).

\begin{tabular}{lccc}
\hline Point & $P_{4 \mathrm{D}}(\mathrm{A})$ & $P_{2 \mathrm{D}}(\mathrm{B})$ & $\mathrm{A} / \mathrm{B}(\%)$ \\
\hline P-1 & -1.12 & -1.11 & 100.29 \\
P-2 & -1.89 & -1.89 & 99.93 \\
P-3 & -2.45 & -2.51 & 97.48 \\
P-4 & -2.63 & -2.67 & 98.67 \\
P-5 & -1.91 & -1.91 & 100.26 \\
P-6 & -2.02 & -2.03 & 99.70 \\
P-7 & -1.10 & -1.10 & 100.03 \\
\hline
\end{tabular}

were positioned at the ground surface centre of the right tunnel. The settlement history curves of all the measuring points on the ground surface settlement monitoring section $(K 0+520)$ are depicted in Figure 15.

According to the construction log, on the 28th day, the stair section at the top of the right tunnel was holed-through, the stair section at the bottom of the right tunnel was excavated to $K 0+560$, and the stair section at the top of the left tunnel was excavated to $K 0+520$. The monitoring results revealed that the ground surface settlement rate decreased after day 30 and tended to stabilise after day 60 . Measuring point No. 9 on the ground surface of the right tunnel exhibited the largest deformation, and the settlement value reached $20 \mathrm{~mm}$, which was greater than that of measuring point No. 10; the settlement of measuring point No. 7 on the ground surface of the existing tunnel was $20 \mathrm{~mm}$, which was the same as that of measuring point No. 9; the settlement of measuring point No. 5 on the ground surface of the left tunnel was $16 \mathrm{~mm}$, which was greater than that of measuring point No. 4 . The maximum ground surface settlement caused by the left/right tunnel excavation disturbance was not observed from the measuring points at the ground surface centre of the two tunnels but near the centre of the existing tunnel; this is consistent with the model test conclusion. The ground surface settlement values of all the measuring points tended to $20 \mathrm{~mm}$, which was slightly greater than the obtained value of $14.88 \mathrm{~mm}$. This may be attributed to the fact that the surrounding rock material was homogeneous in the model test, and the influence of factors-such as the accelerated weathering of the surrounding rock after being disturbed by the existing tunnel construction-was not considered. The model test results and the monitoring measurement results were considered consistent; during the entire construction and excavation process of the short shallow tunnel, the surrounding rock and ground surface settlement of the tunnel were continuously disturbed and the monitoring measurements agreed with the model test results.

Particularly, the monitoring and measurement of the ground surface settlement of the existing tunnel at measuring point No. $7(20 \mathrm{~mm})$ were the same as at the ground surface at the top of the right tunnel and were significantly larger than the settlement value measured in the model test $(5.52 \mathrm{~mm})$; this may be due to the number and density of cracks in the surrounding rock of the shallow tunnel increasing under the disturbance due to the construction of the existing tunnel; furthermore, more than 20 years of weathering erosion of the surrounding calcareous rock by groundwater and other factors had worsened the stability of the surrounding rock; therefore, the ground surface settlement increased after being disturbed by the construction of the tunnel reconstruction and expansion project. This indicates that, for the focus of this study-wherein, the tunnel was short and the burial depth was shallow-the ground surface was always affected during the excavation process of the left and right tunnels and the loose rock zone reached the ground surface; the decrease in surrounding rock pressure observed in the model test verified the presence of the loosening rock zone caused by tunnel excavation, which agreed with the actual situation. In the construction of similar projects in the future, the surrounding rock level can be regarded as one level below that obtained from the geological survey results; accordingly, the support parameters of the tunnel should be strengthened and the construction plan should be optimised to ensure the safety of the tunnel reconstruction and expansion project.

It is evident from the consistent results of the model test and the three-dimensional numerical simulation that the excavation of the second tunnel causes a larger surface settlement than that of the first tunnel. Therefore, it is necessary to carefully monitor the surface settlement during the excavation of the second tunnel. The excavation of both tunnels has a significant effect on the stability of the 


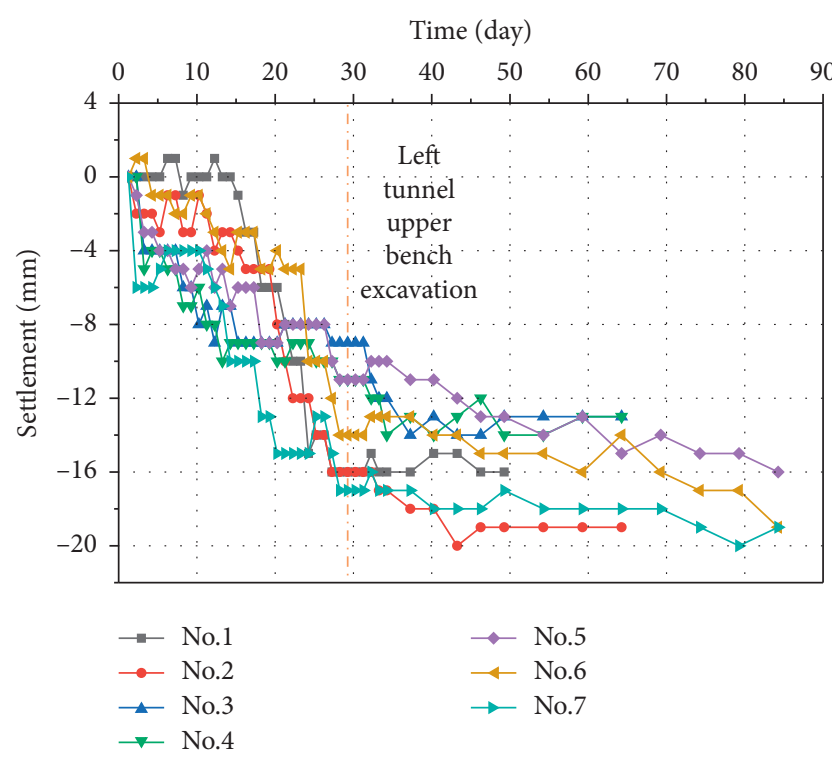

(a)

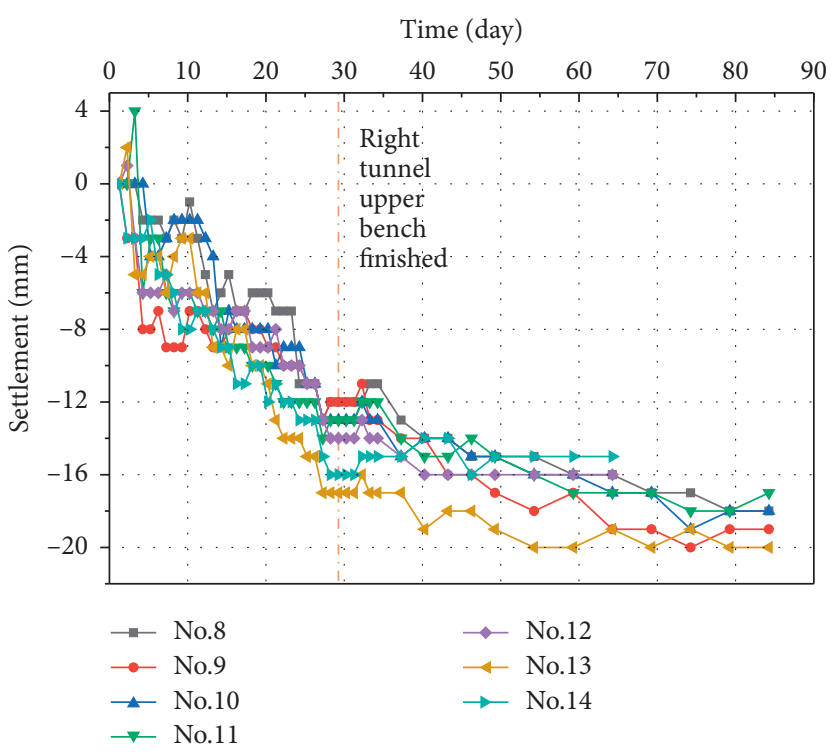

(b)

FIGURE 15: Ground surface settlement history curves of all measuring points. (a) Ground surface settlement history curves of measuring points on top of left tunnel. (b) Ground surface settlement history curves of measuring points on top of right tunnel.

surrounding rock and the mechanical deformation of the midwall and supporting structures within the range of a single-tunnel span behind the tunnel face; hence, the stresses and deformation of the midwall and supporting structures should also be carefully monitored within this range.

5.2. Design and Construction Optimisation. According to the geological survey results and referring to the "Specifications for Design of Highway Tunnels" (JTG 3370.1-2018), the initial design parameters of the current project were as follows: the C25 shotcrete thickness of $15 \mathrm{~cm}$, anchor spacing of $120 \mathrm{~cm}$, midwall thickness of $240 \mathrm{~cm}$, secondarylining thickness of $40 \mathrm{~cm}$, and reinforcement ratio of the reinforced concrete structure of $1.0 \%$; the initial construction scheme utilised a layer-by-layer excavation method. While performing the model test using the initially designed support parameters, a large crack appeared, even before completing the excavation of the lining model; as a result, the test failed and did not obtain the complete data. Combined with the research results of this study, the reference support parameters given in the standard code were not applicable to the relying project.

This study adjusted the design parameters as follows: C25 shotcrete thickness of $25 \mathrm{~cm}$, I14 spacing of $150 \mathrm{~cm}$; midwall thickness of $240 \mathrm{~cm}$, secondary lining thickness of $45 \mathrm{~cm}$, and reinforcement ratio of the reinforced concrete structure of $1.5 \%$; the construction scheme was adjusted for full-face excavation method. Both the model test and the monitoring measurement results demonstrated that the rock loosening range could reach the ground surface during the reconstruction and expansion of the existing shallow single-hole tunnel into a twin-arch tunnel; the midwall and the lining structures were most significantly disturbed by the construction; in particular, the height of the midwall reached $8.3 \mathrm{~m}$, structural stress showed complicated changes near the midwall, and stress concentrations were observed in some areas, the local stresses of which had exceeded the ultimate tensile strength of the C25 concrete. According to the research results of this study, the reinforcement ratio of the midwall and secondary lining was adjusted to $2.0 \%$ to ensure the safety and durability of the reinforced concrete structure. When performing the model test using the adjusted support parameters, the structure was stable and the construction efficiency was significantly improved while ensuring safety. According to the optimised and adjusted design and construction plan, the construction period of the project was shortened by approximately two months, which considerably relieved the tourism traffic pressure in the city where the project was located. At present, this project has been running safely for four years; midwall and linings have had relatively few structural issues, operating and maintenance costs have been controllable, and overall performance has been satisfactory.

\section{Conclusions}

To address the issues of surrounding rock and structural deformations during the reconstruction and expansion of an existing shallow single-hole tunnel into a twin-arch tunnel, we developed a tunnel excavation model test system that can be used repeatedly for different surrounding rocks, excavation footages, and excavation time steps. The test results indicated the effectiveness of this system, which was successfully applied in the tunnel reconstruction and expansion model test. The conclusions are detailed as follows:

(1) The results of the ground surface settlement values and their variations were obtained, respectively, from construction monitoring and measurement, as well as a model test; a comparison between the two revealed that except for the ground surface at the top 
of the midwall-where the measured value from monitoring and measurement was greater than that from the model test-the results from the other measuring points were consistent; this may be because the surrounding calcareous rock was weakened after being disturbed by the construction of the existing tunnel by the accelerated weathering under the action of water and other factors, thereby increasing the ground surface settlement; however, the weathering of surrounding rocks could not be simulated by the model test. The settlement values and their variations obtained from the two tests could be considered consistent and mutually verified; the results were credible.

(2) The existing tunnel served as the middle guide tunnel to construct the midwall, the height of which was greater than the new tunnel. The wall had a large contact area with the lining. Its structural internal stress was significantly affected by the tunnel excavations; this was particularly applied to the second tunnel. The resulting effect on the structure was that the tensile stress easily exceeded the limit, affecting the stability and durability of the structure; thus, attention should be paid to increase the structural support parameters in the design and reduce disturbances in the construction.

(3) The excavation of both tunnels had a significant effect on the stability of the surrounding rock within the distance of a single-tunnel span behind the tunnel face; thus, the stresses and deformation of the surrounding rock and supporting structures must be carefully monitored within this range. When the excavation distance between the first and second tunnels exceeded two single-tunnel spans, the excavation distance had a negligible effect on the stress and deformation of the reconstructed twin-arch tunnel.

(4) The suggested support parameters given in the "Specifications for Design of Highway Tunnels" (JTG 3370.1-2018) were not applicable for reconstructing and expanding an existing shallow single-hole tunnel into a large-span twin-arch tunnel. Under the guidance of this model test research, the parameters of the preliminary lining, as well as the reinforcement ratio of the secondary lining and midwall, were increased; the construction scheme was also optimised for the relying project. The construction progress was accelerated while ensuring structural safety. At present, this project has been completed and has been running smoothly.

\section{Data Availability}

The data used to support the findings of this study are included within the article.

\section{Conflicts of Interest}

The authors declare that there are no conflicts of interest regarding the publication of this paper.

\section{Acknowledgments}

This research was supported by the Guangxi Scientific Research and Technology Development Plan Project (no. Guikegong 1355008-3).

\section{References}

[1] C. Zhi-Long, C. Jia-Yun, H. Liu, and Z.-F. Zhang, "Present status and development trends of underground space in Chinese cities: evaluation and analysis," Tunnelling and Underground Space Technology, vol. 71, pp. 253-270, 2018.

[2] A. Valipour, M. Yadollahi, and Z. R. Mohamad, "An enhanced multi-objective optimization approach for risk allocation," Canadian Journal of Civil Engineering, vol. 41, no. 2, pp. 164-177, 2013.

[3] W. Xie and Y. Xiong, "The operation security hazard prediction in high slope construction of freeway reconstruction and extension based on T-S fuzzy neural networks," Transportation Science \& Technology, vol. 2015, no. 1, pp. 173-176, 2015.

[4] J. Tang, F. Liu, W. Zhang, S. Zhang, and Y. Wang, "Exploring dynamic property of traffic flow time series in multi-states based on complex networks: phase space reconstruction versus visibility graph," Physica A: Statistical Mechanics and Its Applications, vol. 450, pp. 635-648, 2016.

[5] J. B. M. Admiraal, "Planning the use of underground space: asset or liability," in Proceedings of ITA World Tunnelling Congress, Vancouver, Canada, October 2010.

[6] J. E. Leisch, "Planning/design features and case studies in freeway reconstruction," ITE Journal, vol. 10, pp. 14-23, 1983.

[7] P. Lunardi, "Widening the Nazzano motorway tunnel from two to three lanes + an emergency lane without interrupting traffic," Avances Tecnológicos Einnovación, vol. 3, pp. 894-905, 2012.

[8] G.-Q Zhu, L. Z. Yu-Cai, and Y. Cheng, "Research on influences of in-situ tunnel extension project on adjacent buildings," Rock and Soil Mechanics, vol. 2, pp. 257-262, 2012, in Chinese.

[9] Y. Meng, "Redevelopment of urban transportation in the city center-Boston's central artery/tunnel project," Urban Planning Overseas, vol. 21, no. 2, pp. 87-91, 2006.

[10] L. Hong-Peng, X. Xue-Shen, and R.-C. Chang, "Study on mechanical characteristics of highway tunnel expansion," China Journal of Highway and Transport, vol. 27, no. 1, pp. 84-93, 2014, in Chinese.

[11] L. Sun, The Experimental Study and Theoretical Analysis on Mechanical Behaviour of Widening Highway Tunnel, Chang'an University, Xi'an, China, 2012.

[12] H. Lun-Hai and Q. Qi-Hu, "Study on excavation schemes for the redevelopment construction of highway tunnels with large sections," Modern Tunnelling Technology, vol. 53, no. 5, pp. 145-153, 2016, in Chinese.

[13] W. Zhang-Zhong, G.-L. Xu, and L. Wu, "Mechanical deformation characteristics of rock mass surrounding lateral enlarging excavation of tunnels with ultra-large sections," Chinese Journal of Geotechnical Engineering, vol. 31, no. 2, pp. 172-177, 2009, in Chinese.

[14] Q.-S. Liu, X.-S. Sun, and S. Xing-ju, "Optimal analysis of construction schemes for Houci extension tunnels with large span," Engineering Journal of Wuhan University, vol. 49, no. 4, pp. 544-551, 2016, in Chinese. 
[15] X. Xue, Study of the Expansion Type and Stability of Highway Tunnel Change, Chongqing Jiaotong University, Chongqing, China, 2016.

[16] X. Li, Comparison and Selection of Reconstruction and Expansion Schemes for In-Service Tunnels in the Loess Area, Chang'an University, Xi'an, China, 2019.

[17] S. C. Li, S. F. Wang, and W. S. Zhu, "Research on numerical simulation of deformation of soft rockmass tunnels in Taiwan," Chinese Journal of Geotechnical Engineering, vol. 23, no. 5, pp. 540-543, 2001, in Chinese.

[18] Y. Jia, Y. Xia, and X. Han, "Application of hangar tunnel in disaster prevention of road high slope," Journal of Jiangsu University (Natural Science Edition), vol. 39, no. 6, pp. 714720, 2001, in Chinese.

[19] Chongqing Communications Research \& Design Institute, JTG 3370.1-2018 Specifications for Design of Highway Tunnels, China Communications Press, Beijing, China, 2004, in Chinese.

[20] J. Lai, J. Qiu, H. Fan et al., "Structural safety assessment of existing multiarch tunnel: a case study," Advances in Materials Science and Engineering, vol. 2017, Article ID 1697041, , 2017.

[21] G. Lin and C. He, "Study on the reasonable construction method for a twin-arch road tunnel," Modern Tunnelling Technology, vol. 40, no. 6, pp. 713-718, 2003, in Chinese.

[22] X. Lin-Ping, Y.-G. Zhao, and Y.-S. Shen, "Model experimental study on style of structural internal force and stability of surrounding rock in twin-arch tunnel," Chinese Journal of Rock Mechanics and Engineering, vol. 24, no. 23, pp. 43464351, 2005, in Chinese.

[23] T. Liu, M.-R. Shen, and L.-B. Tao, "Model test and 3D numerical simulation study on excavation of twin-arch tunnel," Chinese Journal of Rock Mechanics and Engineering, vol. 25, no. 9, pp. 1802-1808, 2006, in Chinese.

[24] L. Shu-Chen, C. Yuan, and L. Shu-Cai, "Model test study on mechanical behavior of extremely shallow twin-arch tunnel during excavation," Journal of China Coal Society, vol. 37, no. 5, pp. 713-718, 2011, in Chinese.

[25] L. Tian, Q. Duan, and Q. Xu, "Analysis and research on laboratory model test for twin-tunnel under unsymmetrical pressure," Chinese Journal of Underground Space and Engineering, vol. 9, no. 1, pp. 119-125, 2013, in Chinese.

[26] F. Gao and D.-L. Xue, "Twin-arch tunnel construction in large span bias weak surrounding rock," Journal of Chongqing Jiaotong University (Natural Science), vol. 33, no. 2, pp. 30-34, 2014, in Chinese.

[27] J. Zhang, K. Sun, and F. Lu, "Model test study of surrounding rock pressure distribution and mechanical characteristics of unequal-span double -arch railway tunnel," Rock and Soil Mechanics, vol. 36, no. 11, pp. 3077-3093, 2015, in Chinese.

[28] X. R. Liu, J. Liu, and L. H. Huang, "Model test and pressure arch analysis for excavation of loess double arch tunnel," Journal of Zhejiang University: Engineering Science, vol. 52, no. 6, pp. 1140-1141, 2018, in Chinese.

[29] Z. Mao, X. Wang, N. An, X. Li, and R. Wei, "Water disaster susceptible areas in loess multi-arch tunnel construction under the lateral recharge condition," KSCE Journal of Civil Engineering, vol. 23, no. 10, pp. 4564-4577, 2019.

[30] X. Li, Y. Xiang, and H. Qiao, "Study on failure mode of shallow multi-arch tunnel," in Proceedings of the International Conference on Mechanical, Electrical and Information Technology (ICMEIT 2018), pp. 609-613, Guangzhou, China, December 2018.

[31] J. Zhang, C. Zhang, C. Wang, and J. Shi, "Study on bias characteristics of multi arch tunnel under different side overburden thickness," in Proceedings of the 5th International Conference on Environmental Science and Civil Engineering (ESCE2019), Nanchang, China, April 2019. 